\title{
A Novel Sensorless Control for Multiphase Induction Motor Drives Based on Singularly Perturbed Sliding Mode Observer-Experimental Validation
}

\author{
Mahmoud A. Mossa ${ }^{1, * \mathbb{C}}$, Hamdi Echeikh ${ }^{2}$, Atif Iqbal ${ }^{3}{ }^{\mathbb{D}}$, Ton Duc Do ${ }^{4}$ and \\ Ameena Saad Al-Sumaiti ${ }^{5}$ \\ 1 Electrical Engineering Department, Faculty of Engineering, Minia University, Minia 61111, Egypt \\ 2 Electrical Engineering department, National Engineering School of Monastir, Monastir 5035, Tunisia; \\ echeikh_hamdi@hotmail.com \\ 3 Department of Electrical Engineering, Qatar University, Doha 2713, Qatar; atif.iqbal@qu.edu.qa \\ 4 Department of Robotics and Mechatronics, School of Engineering and Digital Sciences (SEDS), \\ Nazarbayev University, Nur-Sultan 010000, Kazakhstan; doduc.ton@nu.edu.kz \\ 5 Advanced Power and Energy Center, Electrical Engineering and Computer Science, Khalifa University, \\ Abu Dhabi 127788, UAE; ameena.alsumaiti@ku.ac.ae \\ * Correspondence: mahmoud_a_mossa@mu.edu.eg; Tel.: +20-12-2991-2291
}

Received: 28 January 2020; Accepted: 4 April 2020; Published: 16 April 2020

\begin{abstract}
This paper aims to develop an innovative sensorless control approach for a five-phase induction motor (IM) drive. The operation principle of the sensorless scheme is based on the sliding mode theory, within which a sliding mode observer (SMO) estimates the speed and rotor resistance simultaneously. The operation methodology of the proposed control technique is formulated using the mathematical model of the machine and the two-time-scale approach. The observation technique offers a simple and robust solution of speed and rotor resistance estimation for the sensorless control approach of the multiphase drive. The paper considers the five-phase induction motor (IM) as a case study; however, the proposed control algorithm can be employed by different types of multiphase machines. To test the applicability of the proposed sensorless control approach, the drive performance is firstly validated using MATLAB/Simulink-based simulation. Then, the simulation results are verified using real-time simulation and experimentally using TMS320C32 DSP-based control board. The obtained results confirm and validate the ability of the proposed control procedure in achieving a robust dynamic performance of the drive against the system uncertainties such as parameter variation.
\end{abstract}

Keywords: multiphase machine; five-phase IM; sliding mode observer; sensorless operation; experimental validation

\section{Introduction}

The segmentation of the power in the multiphase system tends to limit the voltages and currents amplitudes that are applied to the individual phases. It is recommended to size the current of power inverters' legs because this helps in reducing the size of components while eliminating the problems caused by their association in parallel [1-4]. For a given power rate, when increasing the number of phases, the phase current decreases without increasing the voltage per phase (or vice versa). The total power is then distributed over a greater number of phases; and consequently, the power required by each of them is reduced. Thus, the machine can be supplied by a power inverter that can be constructed by a lower-class of power components that are capable of operating at higher switching frequencies. This allows the minimization of current and torque ripples. The power segmentation is the advantage 
of the multiphase machine that is considered the most desired requirement nowadays, especially for high power applications.

High-performance control of induction motors requires precise knowledge of the rotor position. This information can be provided by mechanical sensors, i.e., dynamo tachometer, digital incremental encoder, etc. However, using mechanical sensors introduces several drawbacks. These drawbacks include the increase of the volume, the overall cost of the system, and also the reduction of the system reliability. In addition, mechanical sensors require a stub shaft to be used with it [5-10]. For all these reasons, it is interesting to eliminate the sensors. Recently, the operation without a mechanical speed sensor (sensorless) of induction motors has become one of the main attractions of interest for researchers and industrialists. They can be subdivided into two different families of strategies: the first is concerned with estimating the speed without using the machine model. These strategies have been articulated in the extraction and analysis of harmonics in the rotor slots and injecting a high frequency signal. The second method is based on observing the speed using the machine model. In this type, the design of observers is mainly articulated on the IM model and thus the observer is considered as a mirror to the machine model. In literature, many speed sensorless techniques have been proposed. The essential ones are the Extended Kalman filter [11-21], the adaptive reference model (MRAS) [22-24], the Luenberger observer [25-28], the high gain observer [29], the sliding mode observer [30-33], and the backstepping observer [34-37]. The dominance of a particular method articulates mainly on the accuracy of speed estimation. For example, the model dependent estimation techniques are defined by its simplicity. However, the sensitivity to the system uncertainties is considered the dominant problem of these observers. The resistances of stator and rotor windings are playing a vital role during the estimation and for this reason; their values must be identified accurately to achieve precise speed estimation [38]. Indeed, estimation of speed without model requires an analysis of the spectrum to increase the speed control band. Therefore, the program becomes complex and requires more time for execution. The simplicity and effectiveness of the observers based on the model becomes an open subject for several researchers.

Currently, flux-oriented control of IM drives is extensively used in the applications which required high performance. Nonetheless, the drive performance is negatively affected when the parameters are varied. The performances of the controller and observer are immediately downgraded in the existence of these uncertainties. Notably, the behavior of the control system is highly attentive to the state estimator. In order to manage these uncertainties, the online parameter identification has to be considered. An adaptive or robust conception strategy can be used for designing either the estimator and/or the controller schemes. To this consideration, in [39-41], both the rotor and stator resistances are estimated online involving neural networks, two extended Kalman filters, and modified extended Kalman filter, respectively. Although in [42], only stator resistance is estimated using an extended Kalman filter. The majority of these studies have guaranteed that the resistances of the rotor and stator coils and also the mutual inductances are obtainable. In [39], the rotor and stator resistances are observed by using several designs based on two different neural networks which are established starting from the IM model, where the authors revealed that the speed estimation is very sensitive to the system disturbance, which must be filtered. In [43], the stator currents and rotor flux are estimated using a sliding mode observer (SMO) observer, operated by the mismatch between the observed and measured stator currents. Through analyzing the performance of these observers, the SMO has revealed the most appropriate performance in achieving a robust estimation versus different types of disturbances; however, the obtained estimations have suffered from the chattering phenomenon. Another category of observers has been dependent on the adaptive mechanism, and known by the name of reference adaptive model control strategies [44-46]. These observers have depended on extracting the rotor position and speed information from the error between two estimated values of rotor flux. The problems associated with these observers are mainly the high sensitivity to the parameters variation, which deteriorates the estimation accuracy especially at very low speed range. Attempts 
have been made to compensate the effect of parameters variation through developing a mechanism for estimating the varied parameters as in [45,46], but this led to increasing the system complexity.

Up to this review, and in order to avoid the previous deficiencies, the singular perturbation theory is employed and combined with the traditional indirect rotor-field oriented control (IRFOC) technique in order to achieve better system dynamics with parametric uncertainties. This has been achieved through formulating the state observation process in two different stages. First, a simultaneous observation of both rotor flux and rotor speed is adopted and secondly the rotor resistance observation is integrated to enhance the robustness of the sensorless scheme.

The contributions of the intended sensorless observation mechanism can be summarized as follows.

(i) A novel singularly perturbed sliding mode observer is proposed for a five-phase induction motor drive for estimating the speed and rotor resistance.

(ii) The design procedure of the proposed SMO observer is presented and explained in a detailed way which contributes in clarifying the base principles upon which the observer depends.

(iii) Load torque estimation is not required, which simplifies the observer construction.

(iv) State estimation procedure does not involve mechanical equations. Therefore, the proposed scheme does not use nonlinear estimation equations.

(v) The rotor resistance and speed are estimated simultaneously, so that the effect of parametric variation can be minimized.

(vi) The singular perturbation theory used in this paper essentially works on two-time-scale system with slow and fast subsystems which simplifies the control system design and the structural analysis as well. Accordingly, the two lower order control and observer subsystems can be designed and finally merged to yield a combined observer system. This contributed effectively in enhancing the robustness of the controller against system uncertainties.

(vii) In order to validate the feasibility of the proposed SMO observer, extensive simulation and experimental tests are carried out for a wide range of speed variation considering the parameters mismatch. The robustness of the observer is present for the all considered operating regimes.

(viii) The proposed SMO observer can be easily extended to be used by different types of multi-phase machine drives after considering the construction and base operation of each type.

The structure of the paper is given as follows. The generality of the proposed method and theory of singularly perturbed systems is discussed in Section 2. In Section 3, the design of two-time-scale sliding mode observer is developed. Section 4 presents two parts: modeling the five-phase IM and developing the SMO for estimating the rotor resistance and speed. Section 5 presents the tests that are carried out to validate the applicability of the proposed sensorless control approach. Section 6 presents a summary for the results discussion, and Section 7 summarizes the outcomes of the study.

\section{Technique of Two-Time-Scale}

The two-time-scale technique divide the system dynamic into two different sub-dynamics: fast and slow ones $[40,42]$. To distinguish between the two sub-dynamics, a scalar $\zeta$ needs to be calculated. This scalar refers to the slow speed to fast speed ratio and which is supposed to be with a small value. Generally, the slow and fast states are inherently associated with two time scales $t$, respectively $[47,48]$.

Then, the relationship between the time scale $\tau$ and the time scale $t$ can be expressed by

$$
\tau=\frac{t-t_{0}}{\zeta}
$$

where $t_{0}$ is the initial time. 


\subsection{Nonlinear SP Systems}

The class of SP nonlinear systems can be represented as follows,

$$
\left\{\begin{array}{c}
\dot{x}=f(t, x, z, \zeta, u), x\left(t_{0}\right)=x_{0} \\
\zeta \dot{z}=g(t, x, z, \zeta, u), z\left(t_{0}\right)=z_{0}
\end{array}\right.
$$

where the slow and fast states are designed by $z \in R^{m}$ and $x \in R^{n}$, respectively. The control input is given by $u \in R^{p}$ with $\zeta \in[0,1]$. Moreover, the variable $y=z$ with $y \in R^{m}$ represents the measurement vector which is linearly associated with the fast state vector.

\subsection{Slow Subsystem Dynamics}

The nonlinear system described by Equation (2) combines the fast and slow subsystems, where $\mathrm{z}$ is the fast vector component and $\mathrm{x}$ is the slow vector component. Then, to reduce the system's complexity, the Tikhonov's theorem is utilized [49]. By putting $\zeta \rightarrow 0$ in Equation (2), then the reduced order model in the $t$ time-scale described by the quasi-steady-states $z_{s l}(t)$ and $x_{s l}(t)$ can be expressed by

$$
\left\{\begin{array}{c}
\frac{d x_{s l}}{d t}=f\left(t, x_{s l}, z_{s l}, u_{s l}, 0\right) \\
0=g\left(t, x_{s l}, z_{s l}, u_{s l}, 0\right)
\end{array}\right.
$$

Moreover, by putting $z_{s l}=h\left(t, x_{s l}, u_{s l}\right)$ and by replacing the root of the second equality of (3) into the first equality of (3), the reduced order model can be then expressed by

$$
\left\{\begin{array}{c}
\frac{d x_{s l}}{d t}=f\left(t, x_{s l}, h\left(t, x_{s l}, u_{s l}\right), u_{s l}, 0\right) \\
x_{s l}\left(t_{0}\right)=x_{0}
\end{array}\right.
$$

where the subscript $(s l)$ reveals that the quantity is related to the system without a scalar $\zeta$.

\subsection{Fast Subsystem Dynamics}

The variable $z_{f s}$ refers to the fast dynamics, which is obtained through deriving $z_{s l}$ from $z$. This can be accomplished through the transition between the slow $t$ and the fast $\tau=\left(t-t_{0}\right) / \zeta$ time scales. Then, the system described by (2) can be reformulated by

$$
\left\{\begin{array}{l}
\frac{d x}{d \tau}=\zeta f\left(\zeta \tau+t_{0}, x, z, u\right) \\
\frac{d z}{d \tau}=g\left(\zeta \tau+t_{0}, x, z, u\right)
\end{array}\right.
$$

Inserting the term $z_{f s}=z-z_{s l}$ which represents the derivation of $z_{s l}$ from $z$, and identifying the limit as $\varepsilon \rightarrow 0$ results in

$$
\frac{d z_{f s}}{d \tau}=f\left(x_{0}, z_{s l}(0)+z_{f_{s}}(\tau), u_{f s}(\tau), t_{0}\right)
$$

where $z_{f_{s}}(0)=z_{0}-z_{f_{s}}(0)$, and $u_{f s}=u-u_{s l}$ is the fast subsystem of the control input.

\subsection{Approximation of Two-Time-Scale States}

Approximating the initial states of Equation (2) can be performed through combining Equations (4) and (6) of the fast and slow variables in one structure which can be easily handled, and this results in the following expressions

$$
\left\{\begin{array}{c}
x(t)=x_{s l}(t)+O(\zeta) \\
z(t)=z_{s l}(t)+z_{f s}(\tau)+O(\zeta)
\end{array}\right.
$$




\section{SMO Synthesis}

The continuous nonlinear singularly perturbed system of (2) can be expressed by

$$
\left\{\begin{array}{c}
\dot{x}=f(t, x, z, u, \zeta) \\
\zeta \dot{z}=g(t, x, z, u, \zeta)
\end{array}\right.
$$

Furthermore, the above-described system is assumed to be observable. Thus, the state observation of slow variables can be achieved through measuring the fast variables.

\subsection{SMO Conception}

The method is based on substituting the linear correction terms with a discontinuous function as in the case of standard full order observer [50]. Then, by adding additional terms to the nonlinear auxiliary inputs of the system (8), this results in the following relationships,

$$
\left\{\begin{array}{c}
\dot{\hat{x}}=f(\hat{x}, z, \zeta, u)+G_{x} I_{\text {smo }} \\
\zeta \dot{\hat{z}}=g(\hat{x}, z, \zeta, u)+G_{z} I_{\text {smo }}
\end{array}\right.
$$

where the switching function $I_{s m o}$ is given by $I_{s m o}=\operatorname{sign}(S(y, \hat{y}))$ and $G_{x}$ and $G_{z}$ represent the observer gains to be calculated with dimensions of $(n \times m)$ and $(m \times m)$, correspondingly. In addition, the error $y-\hat{y}$ is selected as a linear function which outlines the dynamics of the sliding surface $S$ by

$$
(y, \hat{y})=\Lambda(y-\hat{y})
$$

where $\Lambda$ is an invariant matrix of dimension $(m \times m)$ to be determined, and

$$
(y-\hat{y})^{T}=\left(\begin{array}{llll}
\left(y_{1}-\hat{y}_{1}\right) & \left(y_{2}-\hat{y}_{2}\right) & \ldots \ldots & \left(y_{m}-\hat{y}_{m}\right)
\end{array}\right)
$$

Subtracting Equation (9) from (8), the error dynamics are given by

$$
\left\{\begin{array}{c}
\dot{e}_{x}=f(x, z, \zeta, u)-f(\hat{x}, z, \zeta, u)-G_{x} I_{s m o} \\
\zeta \dot{e}_{z}=g(x, z, \zeta, u)-G(\hat{x}, z, \zeta, u)-G_{z} I_{s m o}
\end{array}\right.
$$

The expressions (12) can be also rewritten as

$$
\left\{\begin{array}{l}
\dot{e}_{x}=\Delta f-G_{x} I_{s m o} \\
\dot{\zeta}_{z}=\Delta g-G_{z} I_{s m o}
\end{array}\right.
$$

where

$$
\left\{\begin{array}{c}
\Delta f=f(x, z, \zeta, u)-f(\hat{x}, z, \zeta, u) \\
\Delta g=g(x, z, \zeta, u)-g(\hat{x}, z, \zeta, u) \\
e_{x}=x-\hat{x} \\
e_{z}=z-\hat{z}
\end{array}\right.
$$

Now, by applying the singular perturbation methodology and through utilizing the resulted subsystems of (14) and applying them sequentially, the observer's gains can be computed precisely. This computation procedure starts with studying the tracking of fast variables using what is called hit condition (which depends on the measured state variables). Then, the asymptotic-convergent slow variables (for the unmeasured state variables) are analyzed. 


\subsection{Fast Time-Scale Stability Analysis}

The time scale associated with the fast dynamic subsystem is expressed by $\tau=\left(t-t_{0}\right) / \zeta$, then Equation (14) can be reformulated by

$$
\left\{\begin{array}{c}
\frac{d e_{x}}{d \tau}=\zeta\left(\Delta f-G_{x} I_{s m o}\right) \\
\frac{d e_{z}}{d \tau}=\Delta g-G_{z} I_{s m o}
\end{array}\right.
$$

By setting $\zeta=0$ in (15), it yields

$$
\left\{\begin{array}{c}
\frac{d e_{x}}{d \tau}=0 \\
\frac{d e_{z}}{d \tau}=\Delta g-G_{z} I_{s m o}
\end{array}\right.
$$

In order to determine the observer gain $G_{z}$ in (16), the stability analysis in the time scale $(\tau)$ is required. Actually, setting the surface value to zero $(S(\tau)=0)$ is preferred in this time scale. Moreover, when the surface $S(\tau)$ witnesses a sliding mode action, then by solving (16) for $G_{z} I_{s m o}$ ensuring a zero value of $d e_{z} / d \tau$, the auxiliary input value of the discontinuous observer can be evaluated by

$$
G_{z} I_{s m o}=\Delta g
$$

Then, the equivalent switching vector can be calculated by

$$
I_{\text {smo }}=G_{z}^{-1} \Delta g
$$

\subsection{Slow Time-Scale Stability Analysis}

Slow dynamic error can be computed by putting $\zeta=0$ in (13), thus

$$
\begin{gathered}
\frac{d e_{x}}{d t}=\Delta f-G_{x} I_{\text {smo }} \\
0=\Delta g-G_{z} I_{\text {smo }}
\end{gathered}
$$

Moreover, the switching vector can be calculated using (19) as follows,

$$
I_{\text {smo }}=G_{z}^{-1} \Delta g
$$

Thus, via the suitable selection of $G_{x}$, the appropriate rate of convergence $e_{x} \rightarrow 0$ can be achieved.

\section{Design of Two-Time-Scale SMO for Five-Phase IM}

The technique of observer synthesis in two-time-scales sliding-mode, whose measured vector is directly related to the fast variables, is discussed in [49]. The current paper's aim is to determine the slow states from the measured fast states and this can be performed as follows.

This observation method provides a desired system's behavior in a closed loop manner. However, for the ideal case, there is an infinite switching state at the actuators. Yet, there is no aspect of control which can perform this operation. As a result, the high-frequency dynamics are not considered in the system modeling, which led to the appearance of what is called "reluctance" or "chatter" known in Anglo-Saxon under the name of "chattering" and which is characterized by strong oscillations around the sliding surface. To prevent this issue, an area is specified around the sliding surface, in which a slip condition less stringent than the "sign" condition is adopted. In fact, the sign function " $(s)$ " is substituted by a smoother function with variations associated with the saturation function "sat(s)" that can be defined by 


$$
\operatorname{Sat}(S)=\left\{\begin{array}{c}
1 \text { if } S>\chi \\
\frac{S}{\chi} \text { if }|S| \leq \chi \\
-1 \text { if } S<\chi
\end{array}\right.
$$

The boundary layer adjacent to the switching surface has a thickness which is given by the positive constant $\chi$, whereas the rotor speed is treated as a time-changing variable.

\subsection{Mathematical Model of Five-Phase IM}

The mathematical models of the five-phase IM are presented and discussed in several research studies [51]. The dynamic model of the motor can be described using the following differential equations.

$$
\left\{\begin{array}{c}
\frac{d i_{s \alpha}}{d t}=-\frac{R}{\sigma L_{s}} i_{s \alpha}+\frac{L_{m}}{\sigma L_{L} L_{r}} A_{r} \lambda_{r \alpha}+\frac{L_{m}}{\sigma L_{s} L_{r}} \omega \lambda_{r \beta}+\frac{1}{\sigma L_{s}} v_{s \alpha} \\
\frac{d i_{s \beta}}{d t}=-\frac{R}{\sigma L_{s}} i_{s \beta}+\frac{L_{m}}{\sigma L_{s} L_{r}} A_{r} \lambda_{r \beta}-\frac{L_{m}}{\sigma L_{s} L_{r}} \omega \lambda_{r \alpha}+\frac{1}{\sigma L_{s}} v_{s \beta} \\
\frac{d \lambda_{r \alpha}}{d t}=L_{m} A_{r} i_{s \alpha}-A_{r} \lambda_{r \alpha}-\omega \lambda_{r \beta} \\
\frac{d \lambda_{r \beta}}{d t}=L_{m} A_{r} i_{s \beta}+\omega \lambda_{r \alpha}-A_{r} \lambda_{r \beta} \\
\frac{d i_{s x}}{d t}=-A_{s} i_{s x}+\frac{1}{L_{l}} V_{s x} \\
\frac{d i_{s y}}{d t}=-A_{s} i_{s y}+\frac{1}{L_{l s}} V_{s y}
\end{array}\right.
$$

Based on the dynamic model of the motor and singular perturbation theory, the slow variables are represented by the rotor-flux $\alpha-\beta$ components $\left(\lambda_{r \alpha}, \lambda_{r \beta}\right)$, whereas the fast variables are presented by the stator current $\alpha-\beta$ components $\left(i_{s \alpha}, i_{s \beta}\right)$. Consequently, the singularly perturbed model of (22), with $\zeta=\sigma L_{s} L_{r} / L_{m}, x=\left(\begin{array}{cc}\lambda_{r \alpha} & \lambda_{r \beta}\end{array}\right)^{t}, z=\left(\begin{array}{cccc}i_{s \alpha} & i_{s \beta} & i_{s x} & i_{s y}\end{array}\right)^{t}$, can be formulated by

$$
\left\{\begin{array}{c}
\zeta \dot{z}_{1}=-L_{m} A_{r} z_{1}+A_{r} x_{1}+\omega x_{2}+\frac{L_{r}}{L_{m}}\left(v_{s \alpha}-R_{s} z_{1}\right) \\
\zeta \dot{z}_{2}=-L_{m} A_{r} z_{2}+A_{r} x_{2}-\omega x_{1}+\frac{L_{r}}{L_{m}}\left(v_{s \beta}-R_{s} z_{2}\right) \\
\dot{x_{1}}=L_{m} A_{r} z_{1}-A_{r} z_{1}-\omega x_{2} \\
\dot{x_{2}}=L_{m} A_{r} z_{2}+\omega x_{1}-A_{r} x_{2} \\
\dot{z_{3}}=-A_{s} i_{s x}+\frac{1}{L_{l}} v_{s x} \\
\dot{z_{4}}=-A_{s} i_{s y}+\frac{1}{L_{l s}} v_{s y}
\end{array}\right.
$$

where $A_{r}=R_{r} / L_{r}$ and $A_{s}=R_{s} / L_{s}$.

\subsection{Sliding Mode Observer (SMO)}

Using the general approach of singular perturbation of five-phase IM model without incorporating the mechanical part, the mathematical expression of the SMO can be expressed by

$$
\left\{\begin{array}{c}
\zeta \dot{\hat{z}_{2}}=-L_{m} \hat{A}_{r} z_{1}+\hat{A}_{r} \hat{x}_{1}+\hat{\omega} \hat{x}_{2}+\frac{L_{r}}{L_{m}}\left(v_{s \alpha}-R_{s} z_{1}\right)+z_{i \alpha} \\
\zeta \dot{\hat{z}_{2}}=-L_{m} A_{r} z_{2}+\hat{A}_{r} \hat{x}_{2}-\hat{\omega} \hat{x}_{1}+\frac{L_{r}}{L_{m}}\left(v_{s \beta}-R_{s} z_{2}\right)+z_{i \beta} \\
\dot{\hat{x}_{1}}=L_{m} \hat{A}_{r} z_{1}-\hat{A}_{r} \hat{x}_{1}-\hat{\omega} \hat{x}_{2}+z_{x \alpha} \\
\dot{\hat{x}_{2}}=L_{m} \hat{A}_{r} z_{2}+\hat{\omega} x_{1}-\hat{A}_{r} x_{2}+z_{x \beta} \\
\dot{z}_{3}=-A_{s} z_{3}+\frac{1}{L_{l s}} v_{s x}+z_{x} \\
\dot{\vec{z}}_{4}=-A_{s} z_{4}+\frac{1}{L_{l s}} v_{s y}+z_{y}
\end{array}\right.
$$


where the accent "'" denotes to the estimated variables, and $\hat{A}_{r}, \hat{x}_{1}, \hat{x}_{2}, \hat{\omega}, \hat{z}_{1}$, and $\hat{z}_{2}$ are the estimated values of $A_{r}, x_{1}, x_{2} \omega, z_{1}$, and $z_{2}$, whereas $z_{i \alpha}, z_{i \beta}, z_{x \alpha}, z_{x \beta}, z_{x}$, and $z_{y}$ are the correction terms which are used for acheiving the desired performance, these terms can be expressed as follows.

$$
\left\{\begin{array}{l}
Z_{i \alpha}=G_{z 1} I_{s m o} \\
Z_{i \beta}=G_{z 2} I_{s m o} \\
Z_{x \alpha}=G_{x 1} I_{s m o} \\
Z_{x \beta}=G_{x 2} I_{s m o} \\
Z_{x}=G_{z 3} T_{s m o} \\
Z_{y}=G_{z 4} T_{s m o}
\end{array}\right.
$$

The switching vectors $I_{s m o}$ and $T_{\text {smo }}$ are chosen as

$$
\begin{gathered}
\left\{I_{\text {smo }}=\left(\begin{array}{c}
\operatorname{sign}\left(S_{1}\right) \\
\operatorname{sign}\left(S_{2}\right)
\end{array}\right)=\left(\begin{array}{l}
\hat{z}_{1}-z_{1} \\
\hat{z}_{2}-z_{2}
\end{array}\right)=\left(\begin{array}{c}
e_{z 1} \\
e_{z 2}
\end{array}\right)\right. \\
\left\{T_{\text {smo }}=\left(\begin{array}{c}
\operatorname{sign}\left(S_{1}^{\prime}\right. \\
\operatorname{sign}\left(S_{2}^{\prime}\right)
\end{array}\right)=\left(\begin{array}{l}
\hat{z}_{3}-z_{3} \\
\hat{z}_{4}-z_{4}
\end{array}\right)=\left(\begin{array}{c}
e_{z 3} \\
e_{z 4}
\end{array}\right)\right.
\end{gathered}
$$

Now, for estimating the speed and flux, the following hypotheses are considered.

Hypothesis 1. Stator voltages and currents are measurable.

Hypothesis 2. Rotor resistance is the only unknown parameter and the rest of motor parameters are known and constant.

Hypothesis 3. The rotor resistance $R_{r}$ is assumed to be unknown quantity and its nominal value is $R_{r n}$.

Hypothesis 4. Motor speed is considered as a time varying unknown bounded variable.

Hypothesis 5. The variation of rotor resistance $R_{r}$ is assumed to be very slow, so that $\dot{R}_{r} \approx 0$.

By setting $e_{z j}=\hat{z}_{j}-z_{j}$ as the estimation current errors for $j \in\left[\begin{array}{llll}1 & 2 & 3 & 4\end{array}\right], e_{x i}=\hat{x}_{j}-x_{j}$ as the estimation flux errors for $i \in[12], \Delta \omega=\hat{\omega}-\omega$ as the estimation speed error, and $\Delta A_{r}=\hat{A}_{r}-A_{r}$ as the rotor time constant estimation error, the estimation error dynamics can be evaluated by subtracting (23) from (24), which results in

$$
\left\{\begin{array}{c}
\zeta \dot{e}_{z 1}=A_{r} e_{x 1}+\omega e_{x 2}+\Delta \omega \hat{x}_{2}+\Delta A_{r}\left(\hat{x}_{1}-L_{m} z_{1}\right) \\
+G_{z 1} I_{s m o} \\
\zeta \dot{e}_{z 2}=A_{r} e_{x 2}-\omega e_{x 1}-\Delta \omega \hat{x}_{1}+\Delta A_{r}\left(\hat{x}_{2}-L_{m} z_{2}\right) \\
+G_{z 2} I_{s m o} \\
\dot{e}_{x 1}=-A_{r} e_{x 1}-\omega e_{x 2}-\Delta \omega \hat{x}_{2}-\Delta A_{r}\left(\hat{x}_{1}-L_{m} z_{1}\right) \\
+G_{x 1} I_{s m o} \\
\dot{e}_{x 2}=-A_{r} e_{x 2}+\omega e_{x 1}+\Delta \omega \hat{x}_{1}-\Delta A_{r}\left(\hat{x}_{2}-L_{m} z_{2}\right) \\
+G_{x 2} I_{s m o} \\
\dot{e}_{z 3}=z_{x}=G_{z 3} T_{\text {smo }} \\
\dot{e}_{z 4}=z_{y}=G_{z 4} T_{s m o}
\end{array}\right.
$$

Using the matrix form, Equation (28) can be expressed as follows,

$$
\left\{\begin{array}{c}
\zeta \dot{e}_{z 12}=A e_{x}-\Delta \omega B \hat{x}+\Delta A_{r}\left(\hat{x}-L_{m} z_{12}\right)+G_{z 12} I_{s m o} \\
\dot{e}_{z 34}=G_{z 34} T_{s m o} \\
\dot{e}_{x 12}=-A e_{x}+\Delta \omega B \hat{x}-\Delta A_{r}\left(\hat{x}-L_{m} z_{12}\right)+G_{x 12} I_{s m o}
\end{array}\right.
$$


where

$$
A=\left(\begin{array}{cc}
A_{r} & \omega \\
-\omega & A_{r}
\end{array}\right)=A_{r} I-\omega B
$$

$I$ is the $(2 \times 2)$ identity matrix and the matrix $B$ is represented by

$$
B=\left(\begin{array}{cc}
0 & -1 \\
1 & 0
\end{array}\right)
$$

Moreover, $G_{z 12}, G_{z 23}$, and $G_{x 12}$ are the observer matrix gains which are determined using the stability analysis of Lyapunov.

\subsection{Stability Analysis}

Via utilizing the two-time-scale technique [52], checking the stability of the system under study and which is described by the matrix gains $G_{s z 1}, G_{z 2}, G_{z 3}$, and $G_{z 4}$ of the measured state variables can be effectively accomplished.

Subsequently, $G_{x 1}$ and $G_{x 2}$ of the slow subsystem or unmeasured states are evaluated so that the reduced-order model when $S \cong \dot{S}=0$ is internally stable.

Using the value of $\tau=\left(t-t_{0}\right) / \zeta$ and after setting the value of $\zeta=0$ in (29), the observation errors can be represented in the form of fast reduced order system as follows,

$$
\left\{\begin{array}{c}
\frac{d e_{z 12}}{d \tau}=A e_{x}-\Delta \omega B \hat{x}+\Delta A_{r}\left(\hat{x}-L_{m} z_{12}\right)+G_{z 12} I_{s m o} \\
\dot{e}_{z 34}=G_{z 34} T_{\text {smo }} \\
\frac{d e_{x 12}}{d \tau}=0
\end{array}\right.
$$

Remark 1. To obtain $S=S^{\prime}=e_{z 12}=e_{z 34}=0$, a precise selection of the matrix gains $G_{z 1}, G_{z 2}, G_{z 3}$, and $G_{z 4}$ must be performed.

Assuming that the flux errors $e_{x 1}$ and $e_{x 2}$ are boundaried in this time-scale and $x$ changes slowly, then by considering the first part of (32), the observer gains matrices can be defined by

$$
\begin{aligned}
G_{z 12} & =\left(\begin{array}{cc}
-\gamma_{1} & 0 \\
0 & -\gamma_{2}
\end{array}\right) \\
G_{z 13} & =\left(\begin{array}{cc}
-\delta_{1} & 0 \\
0 & -\delta_{2}
\end{array}\right)
\end{aligned}
$$

The convergence condition of the sliding surface $S=0$, which is verified by the inequality in (36), can be then expressed by the following formulations.

$$
\begin{gathered}
S^{T} \frac{d S}{d \tau}<0 \\
\left\{\begin{array}{c}
\gamma_{1}>\left|A_{r} e_{x 1}+\omega e_{x 2}+\Delta \omega \hat{x}_{2}+\Delta A_{r}\left(\hat{x}_{1}-L_{m} z_{1}\right)\right| \\
\gamma_{2}>\left|A_{r} e_{x 2}-\omega e_{x 1}-\Delta \omega \hat{x}_{1}+\Delta A_{r}\left(\hat{x}_{2}-L_{m} z_{2}\right)\right| \\
\delta_{1}>\max \left|e_{z 3}\right| \\
\delta_{2}>\max \left|e_{z 4}\right|
\end{array}\right.
\end{gathered}
$$

Proof. Using the definite positive Lyapunov function expressed in (37) and its derivate in the time scale given by (38),

$$
V=\frac{S^{T} S+{S^{\prime}}^{T} S^{\prime}}{2}
$$




$$
\dot{V}=S^{T} \frac{d S}{d \tau}+S^{\prime T} \frac{d S^{\prime}}{d \tau}
$$

Then, via replacing (30) into (38), $\dot{V}$ becomes

$$
\dot{V}=S^{T}\left(A e_{x}-\Delta \omega B \hat{x}+\Delta A_{r}\left(\hat{x}-L_{m} z_{12}\right)+G_{z 12} I_{s m o}\right)+S^{\prime T} G_{z 34} T_{s m o}
$$

Using the values of $G_{z 12}$ and $G_{z 34}$, which are given, respectively, in Equations (33) and (34), the relationship (39) becomes

$$
\begin{aligned}
\dot{V}= & -S_{1}\left(\gamma_{1} \operatorname{sign}\left(S_{1}\right)-A_{r} e_{x 1}-\omega e_{x 2}-\Delta \omega \hat{x}_{2}-\Delta A_{r}\left(\hat{x}_{1}-L_{m} z_{1}\right)\right) \\
& -S_{2}\left(\gamma_{2} \operatorname{sign}\left(S_{2}\right)-A_{r} e_{x 2}+\omega e_{x 1}+\Delta \omega x_{1}-\Delta A_{r}\left(\hat{x}_{2}-L_{m} z_{2}\right)\right) \\
& -S_{1}^{\prime}\left(\delta_{1} \operatorname{sign}\left(S_{1}^{\prime}\right)\right)-S_{2}^{\prime}\left(\delta_{2} \operatorname{sign}\left(S_{2}^{\prime}\right)\right)
\end{aligned}
$$

Taking into account the constraints of all parameters and states of five-phase IM, the derivative of Lyapunov function can be written by

$$
\dot{V}=S^{T} \frac{d S}{d \tau}+S^{\prime} \frac{d S^{\prime}}{d \tau}<0
$$

Remark 2. Once the stator currents access the sliding surface $S=S^{\prime}=e_{z}=0$, the system errors can be evaluated by (29).

Using the system equation of (29) and setting $\zeta=0$ for slow error dynamics, one can write

$$
\left\{\begin{array}{c}
0=A e_{x}-\Delta \omega B \hat{x}+\Delta A_{r}\left(\hat{x}-L_{m} z_{12}\right)+G_{z 12} I_{s m o} \\
\dot{e}_{z 34}=G_{z 34} T_{s m o} \\
\dot{e}_{x 12}=-A e_{x}+\Delta \omega B \hat{x}-\Delta A_{r}\left(\hat{x}-L_{m} z_{12}\right)+G_{x 12} I_{s m o}
\end{array}\right.
$$

Choosing matrices $H=G_{z 12} I_{s m o}, D=G_{z 34} T_{\text {smo }}$, and $M=G_{x 12} G_{z 12}{ }^{-1}$ represented in the real time scale, the relationship (42) becomes

$$
\left\{\begin{array}{c}
0=A e_{x}-\Delta \omega B \hat{x}+\Delta A_{r}\left(\hat{x}-L_{m} z_{12}\right)+H \\
\dot{e}_{z 34}=D \\
\dot{e}_{x 12}=-A e_{x}+\Delta \omega B \hat{x}-\Delta A_{r}\left(\hat{x}-L_{m} z_{12}\right)+M H
\end{array}\right.
$$

Now, by considering the speed as a varying parameter, the Lyapunov function can be then chosen as

$$
V_{l}=\frac{1}{2}\left(e_{x}^{T} e_{x}+\frac{1}{g_{1}}(\Delta \omega)^{2}+\frac{1}{g_{2}}\left(\Delta A_{r}\right)^{2}\right)
$$

where $g_{1}$ and $g_{2}$ are two positive constants.

According to the singular perturbation hypothesis, the speed $\omega$ is assumed to be with a fixed value and it varies with a very slow rate respecting to the change of the rotor flux and stator current. Thus, the derivative of the Lyapunov function $V_{l}$ is obtained from (44) by

$$
\dot{V}_{l}=\dot{e}_{x}^{T} e_{x}+\frac{1}{g_{1}} \Delta \omega \frac{d \hat{\omega}}{d t}+\frac{1}{g_{2}} \Delta A_{r} \frac{d \hat{A}_{r}}{d t}
$$

It is clear that the Lyapunov function $V_{l}$ expressed by (44) is positive definite. Then, by using the first part of (42), the error $e_{x}$ is expressed by

$$
e_{x}=-A^{-1} H+\Delta \omega A^{-1} B \hat{x}-\Delta A_{r} A^{-1}\left(\hat{x}-L_{m} z_{12}\right)
$$


Using (43), the error dynamics $\dot{e}_{x}$ can be derived by

$$
\dot{e}_{x}=(I+M) H=R H
$$

with $R=(I+M)$ By substituting from (46) into (45), the following is obtained,

$$
\dot{V}_{l}=-H^{T} R^{T} A^{-1} H+Q_{1}+Q_{2}
$$

where

$$
\left\{\begin{array}{c}
Q_{1}=\Delta \omega\left(\frac{1}{g_{1}} \frac{d \hat{\omega}}{d t}+H^{T} R^{T} A^{-1} B \hat{x}\right) \\
Q_{2}=\Delta A_{r}\left(\frac{1}{g_{2}} \frac{d \hat{A}_{r}}{d t}-H^{T} R^{T} A^{-1}\left(\hat{x}-L_{m} z_{12}\right)\right)
\end{array}\right.
$$

To satisfy the stability condition of Lyapunov approach, the values $Q_{1}$ and $Q_{2}$ in (48) must be expressed by

$$
\left\{\begin{array}{c}
Q_{1}=\Delta \omega\left(\frac{1}{g_{1}} \frac{d \hat{\omega}}{d t}+H^{T} R^{T} A^{-1} B \hat{x}\right)=0.0 \\
Q_{2}=\Delta A_{r}\left(\frac{1}{g_{2}} \frac{d \hat{A}_{r}}{d t}-H^{T} R^{T} A^{-1}\left(\hat{x}-L_{m} z_{12}\right)\right)=0.0 \\
-H^{T} R^{T} A^{-1} H<0
\end{array}\right.
$$

The condition of the third part of (50) is satisfied by choosing

$$
R^{T} A^{-1}=g_{0} I
$$

with $g_{0}$ is positive constant.

A simple adaptive law for the rotor time constant $\hat{A}_{r}$ and motor speed $\hat{\omega}$ is given by substituting (51) into the first and second parts of (50), and this yields o

$$
\left\{\begin{array}{c}
\frac{d \hat{A}_{r}}{d t}=g_{0} g_{2}\left(G_{z 12} I_{s m o}\right)^{T} B \hat{x} \\
\frac{d \hat{\omega}}{d t}=-g_{0} g_{1}\left(G_{z 12} I_{s m o}\right)^{T}\left(\hat{x}-L_{m} z_{12}\right)
\end{array}\right.
$$

After further simplification of (52), the rotor time constant and speed observer's expressions can be finally defined as the following,

$$
\left\{\begin{array}{c}
\frac{d \hat{A}_{r}}{d t}=g_{0} g_{2}\left(\gamma_{1} \hat{x}_{2} \operatorname{sign}\left(S_{1}\right)-\gamma_{2} \hat{x}_{1} \operatorname{sign}\left(S_{2}\right)\right) \\
\frac{d \hat{\omega}}{d t}=g_{0} g_{1}\left(\gamma_{1}\left(\hat{x}_{1}-L_{m} z_{1}\right) \operatorname{sign}\left(S_{1}\right)\right. \\
\left.+\gamma_{2}\left(\hat{x}_{2}-L_{m} z_{2}\right) \operatorname{sign}\left(S_{2}\right)\right)
\end{array}\right.
$$

The estimated signal $\hat{\omega}$ is considered as a switching function which includes high and low frequency components. The speed can be extracted from the low frequency component [53]. Thus, a low-pass filter can be used to estimate the value of $\hat{\omega}$ as follows,

$$
\hat{\omega}_{l p f}=\frac{1}{1+\kappa \cdot s} \hat{\omega}
$$

where $\kappa$ is the filter's time constant.

\section{RT Real-Time Simulation and Experimental Validation}

The proposed control mechanism is constructed by using six PI controllers; the speed controller is configured with an anti-wind-up to provide a smooth dynamic change for the whole range of speed operation, especially when the speed has a sluggish variation compared with the other electrical variables. Simulations using Matlab/Simulink software and hardware RT simulation tests are performed for the system, which involves the state observation as a feedback variable in order to compute the parameters of the PI controllers. Moreover, the singular perturbation (SP) technique affords a manner to disintegrate the two-time-scale arrangement into slow and fast dynamics in different time scales, 
which remarkably facilitate their architectural reasoning. Correspondingly, the original system is divided into lower-order subsystems with each subsystem has its own control-observer unit, and then the responses of all subsystems are combined to formulate the response of the complete main system. Thus, the concept of combining SP method and SM strategy forms an excellent choice to realize the standard control objectives of the systems, which are characterized by an imprecise model, parametric uncertainties, or parasitic dynamics. For this purpose, the following tests are performed considering the variation of rotor resistance.

The general layout of the proposed control system is illustrated in Figure 1. The indirect rotor field oriented control (IRFOC) is considered as the base principle upon which the proposed control strategy is formulated. Under IRFOC, the rated rotor flux is totally aligned with the direct-axis of the rotating reference frame $\left(\lambda_{r}^{*}=\lambda_{r n}\right)$. In this topology, the load torque is constrained within a definite value and considered as unknown quantity. The designed SMO observer is implemented using the expression (24). The block of adaptive SMO estimates the rotor speed and rotor resistance simultaneously using the adaptive control laws described by Equations (52) and (53), respectively. A low-pass filter described by Equation (54) is utilized to smooth the signal of the estimated speed as the speed signal is containing high frequency components as mentioned earlier. The block of park angle estimation is used to estimate the synchronous frequency $\hat{\omega}_{s}$, which is then used to calculate the synchronous angle $\hat{\theta}_{s}$ needed for the transformation between the coordinate systems. Moreover, all motor parameters are assumed to be constant and known except the speed and rotor resistance. The control parameters and the motor data are listed in Table 1, whereas the parameters of the sliding observer are shown in Table 2.

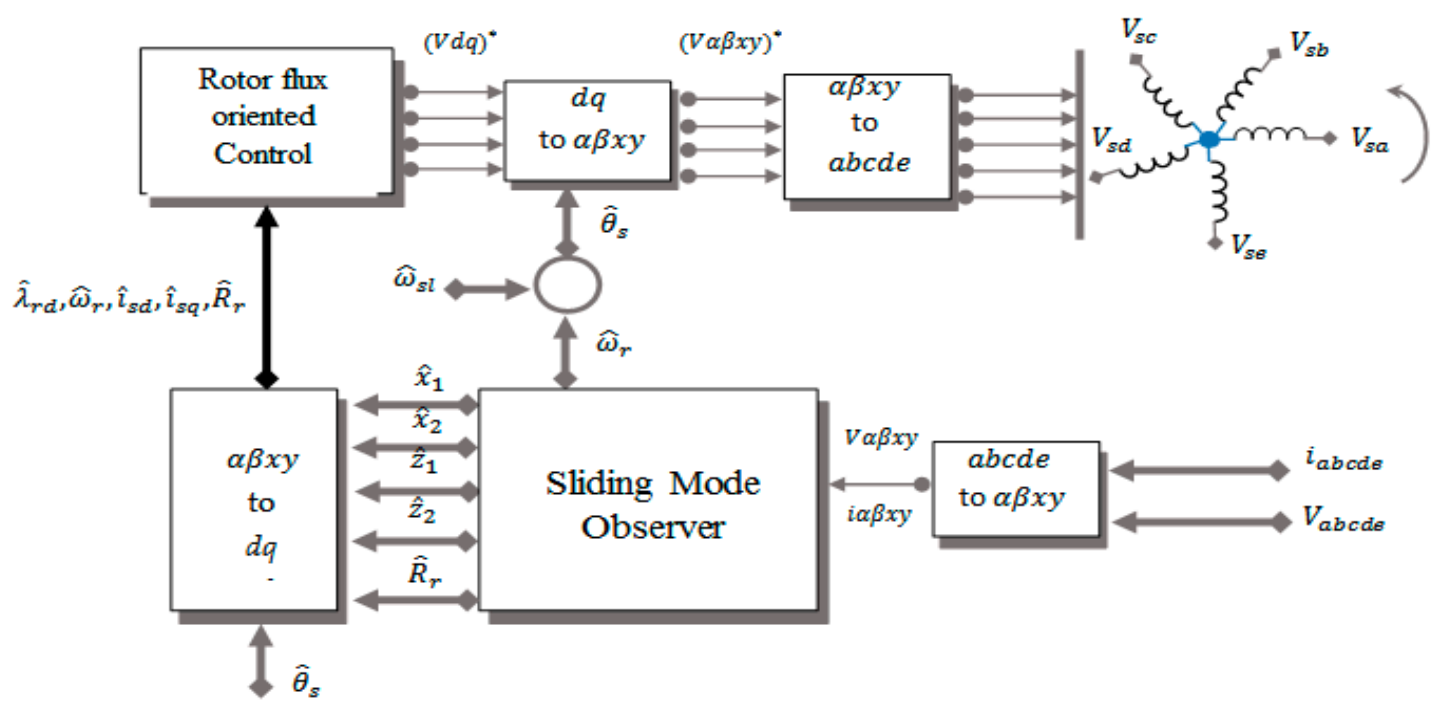

Figure 1. Complete system configuration. 
Table 1. Motor data.

\begin{tabular}{ccc}
\hline Symbols & Quantity & Value \\
\hline$R_{r}$ & Rotor resistance & $2.4 \Omega$ \\
$R_{s}$ & Stator resistance & $2.8 \Omega$ \\
$L_{r}$ & Rotor inductance & $0.2388 \mathrm{H}$ \\
$L_{s}$ & Stator inductance & $0.2388 \mathrm{H}$ \\
$L_{l s}$ & Stator leakage inductance & $0.0088 \mathrm{H}$ \\
$L_{l r}$ & Rotor leakage inductance & $0.0088 \mathrm{H}$ \\
$L_{m}$ & Mutual inductance & $0.23 \mathrm{H}$ \\
$P$ & Pair of Pole & 2 \\
$N$ & Rated speed & $1000 \mathrm{RPM}$ \\
$T n$ & Rated torque & $4 \mathrm{~N} \cdot \mathrm{m}$ \\
$J$ & Inertia moment & $0.008 \mathrm{~kg} \cdot \mathrm{m}^{2}$ \\
$P n$ & Rated Power & $1 \mathrm{~kW}$ \\
\hline
\end{tabular}

Table 2. Sliding mode adaptive observer parameters.

\begin{tabular}{cc}
\hline Symbols & Value \\
\hline$\gamma_{1}$ & 100 \\
$\gamma_{2}$ & 100 \\
$g_{1}$ & 50 \\
$g_{2}$ & 50 \\
$\delta_{1}$ & 150 \\
$\delta_{2}$ & 150 \\
\hline
\end{tabular}

The selected observer parameters must ensure the overall stability of the nonlinear closed-loop system. One must use a high gain for the observer (fast dynamics to be neglected) and a constrained state feedback control (predominate slow dynamics), then the separation between the observer design and state feedback can be achieved [54-57]. To validate the effectiveness of the proposed SMO, the control system shown Figure 1 has been tested using Matlab/Simulink, within which the static Runge-Kutta fourth-order method is utilized to solve the equations which describe the system operation. The estimations of stator currents and rotor fluxes are obtained by solving the relationship (24). To attenuate the chattering, the sampling time is selected as $50 \mu \mathrm{s}$. A PWM technique is used to provide the switching signals to 10 IGBT VSI, with a switching frequency of $10 \mathrm{kHz}$. Under assumptions of availability of all parameters and all states including rotor flux, the estimated values of rotor speed, rotor flux, and rotor resistance are compared with their actual ones. The proposed sensorless control system, including the adaptive laws and SMO, has been testified in hard operating circumstances: speed reversion, rotor resistance mismatch (up to 150\%), high and low speed operation, and load torque change.

\subsection{RT Real-Time Simulation Results}

The RT lab as a real-time simulation tool for prototyping the control system is utilized for verifying the effectiveness of the proposed sensorless control approach. Hardware in the loop RT is referring to the simulations which are executed in real-time and the time needed by the whole procedure (sending the output signals, computation time and reading the input signals,) is in parts of microseconds.

The Opal real-time (RT) simulator is made of software and hardware components. The hardware is made of a command station and a target node which represents the CPU cluster with multi-core quick processors running on real-time environments like QNX or Red Hawk [49]. Meanwhile, the command unit is either a Red hawk PC or a Windows-based interface between the target node and the user. It is utilized to build the concerned model for real time implementation and to monitor the execution and compilation of simulations. The target node used to simulate the specified scheme in real time uses the modular IO module OP5142, which uses the FPGA (Xilinx Spartan-3) processor. It is 
mounted to the rear side of the Wanda $4 \mathrm{U}$ chassis IO module. The OP5142 provides access to four (4) $4 \mathrm{U}$ optical and/or analog I/O modules for conditioning. The processing speed of this module is $100 \mathrm{MHz}$. Figure 2 provides a view of real-time Opal-RT simulator. The proposed control topology is tested using real-time Opal-RT simulator for a 4-pole, $1 \mathrm{~kW}$ five-phase IM with a rated torque of $4 \mathrm{Nm}$.

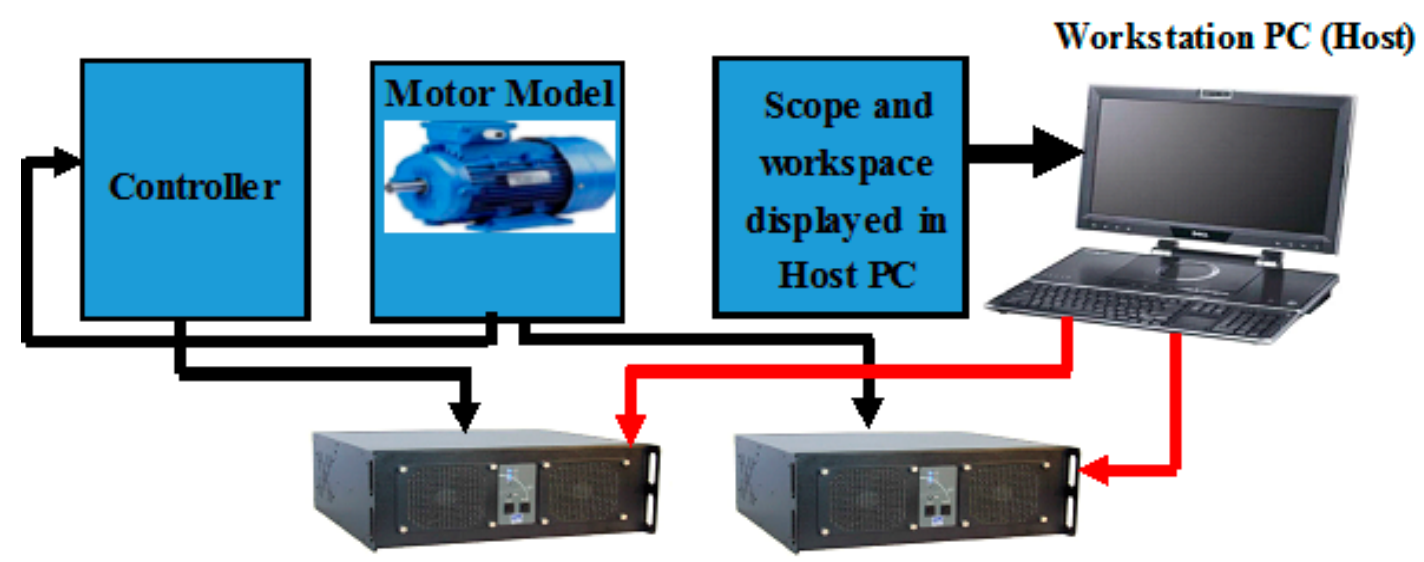

\section{ANALOG and DIGITAL I/O, CAN, FIREWARE}

Figure 2. Block diagram of real time implementation.

The simulation is performed to test the feasibility of the proposed observer while implementing the indirect rotor-field orientation (IRFO) control and investigating the speed tracking performance. The results are illustrated in Figure $3 \mathrm{a}-\mathrm{g}$. The motor started running with its nominal speed and then the speed is reversed, keeping the rotor resistance value $R_{r n}=2.4$. Then, the value of $R_{r}$ is increased and set to $R_{r}=1.5 * R_{r n}$ (This is to investigate the robustness of the proposed SMO against the parameters change.). Figure $3 \mathrm{a}, \mathrm{b}$ presents the speed response (observed and reference) and electromagnetic torque. The estimated speed signal is tracking effectively its reference value with minimum error. Figure $3 \mathrm{c}-\mathrm{e}$ presents the actual and observed stator currents, and through these figures, the validity of the proposed SMO in achieving a precise estimation is confirmed. Figure $3 \mathrm{~d}$ illustrates the reference and observed rotor flux. It is obvious that the observed flux tracks its reference very well even under the variation of the rotor resistance value. The estimated and the actual rotor resistance are also presented in Figure 3f,g. It is noticed that the estimated value is very close to the actual value, and thus one can say that the proposed observer is giving proper results. From these results, it can be concluded that the controller is exhibiting a robust dynamic performance. Moreover, the convergence is obtained for the estimated signals of rotor resistance, rotor speed, and rotor flux, which reveals that the estimation process is well managed with minimum error; meanwhile, the flux orientation is achieved accurately. Table 3 summarized the results obtained using two criteria: the tracking error in the steady state and the convergence time.

Table 3. Convergence time and tracking error of the proposed method.

\begin{tabular}{ccc}
\hline & Tracking Error & Convergence Time \\
\hline Speed estimation & $0 \%$ & $200 \mathrm{~ms}$ \\
\hline Rotor resistance estimation & $0 \%$ & $20 \mathrm{~ms}$ \\
\hline
\end{tabular}



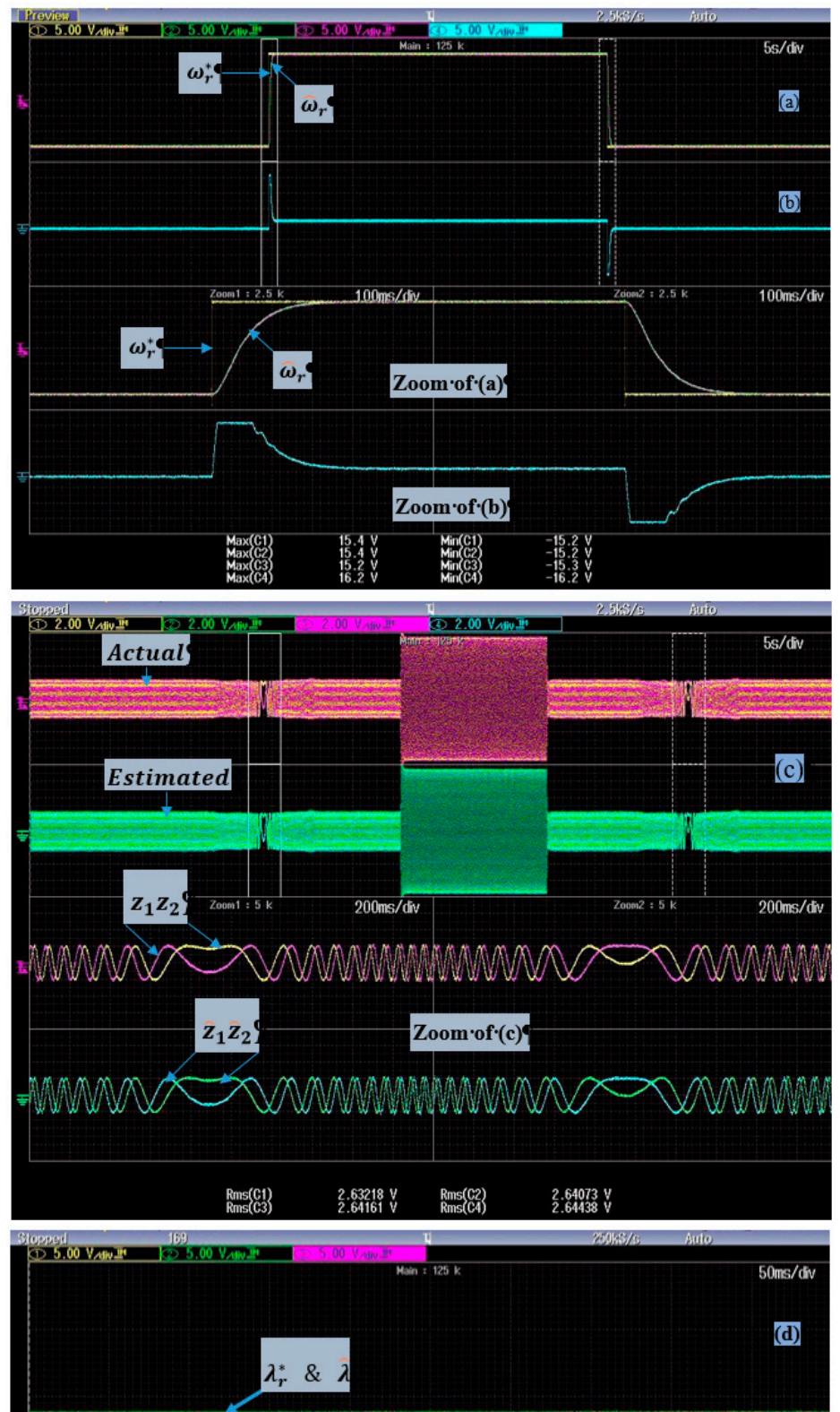

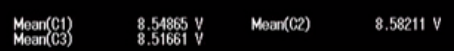

Figure 3. Cont. 

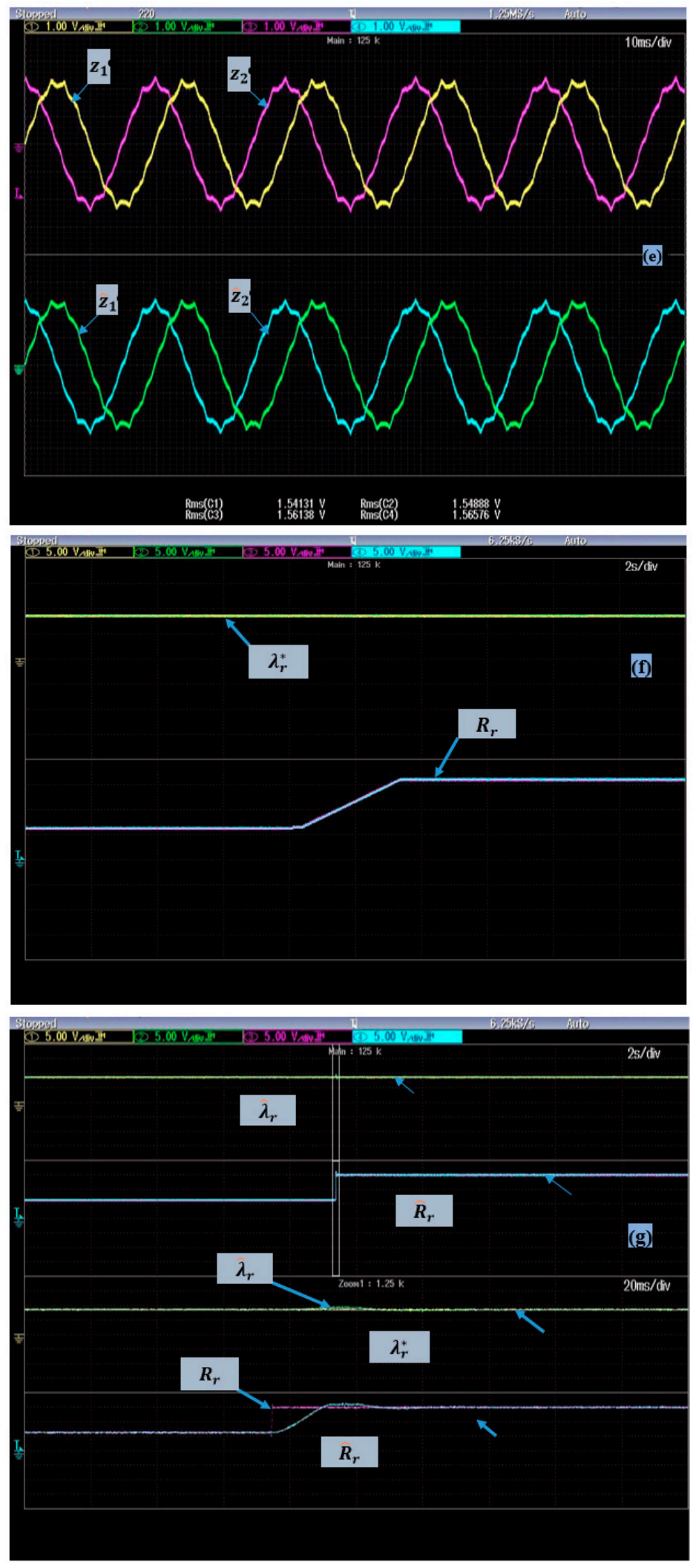

Figure 3. Real time results of sensorless control of five-phase IM drive. (a) Speed, (b) torque, (c) Stator currents (complete view), (d) Rotor flux (Reference and estimated signals), (e) Zoomed view of stator currents (actual and estimated), (f) Rotor flux and rotor resistance variation, (g) Rotor flux dynamics under rotor resistance variation. 
In order to further investigate the effect of rotor resistance variation on the estimated values of rotor flux with and without using the proposed SMO observer, the Matlab/Simulink tool is used for this purpose, and the results are shown in Figure 4. In Figure 4a, a variation in the rotor resistance value is made to $1.5 * R_{r n}$, then the SMO observer is used to track and estimate the resistance. From this figure, it can be realized that the SMO is effectively succeeded in estimating the resistance change with high precision. In Figure $4 b, c$, the estimated values of the rotor flux with and without using the proposed SMO are shown respectively. From these figures, it can be concluded that the proposed SMO plays a vital role in estimating the rotor flux under the system uncertainties.

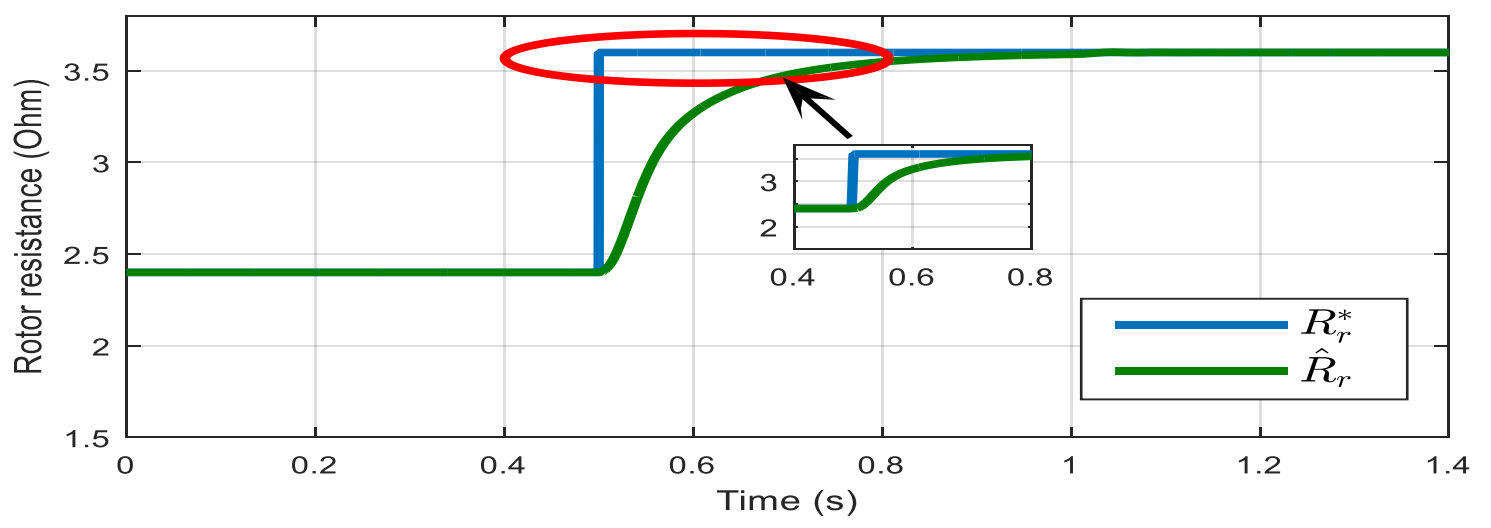

(a)

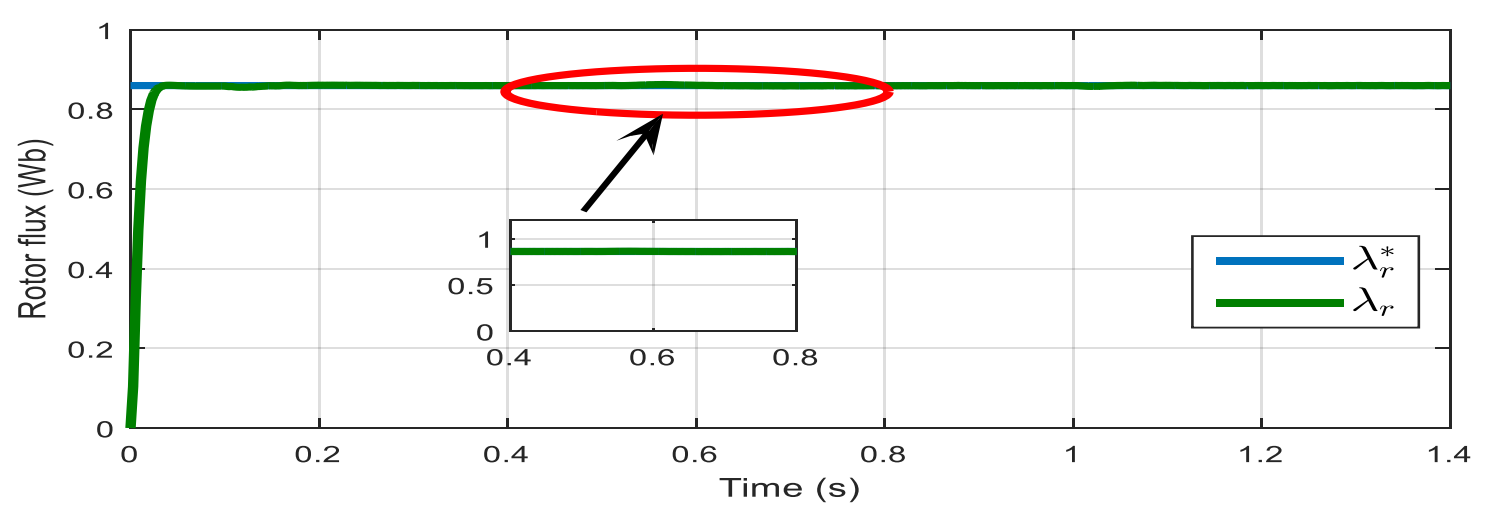

(b)

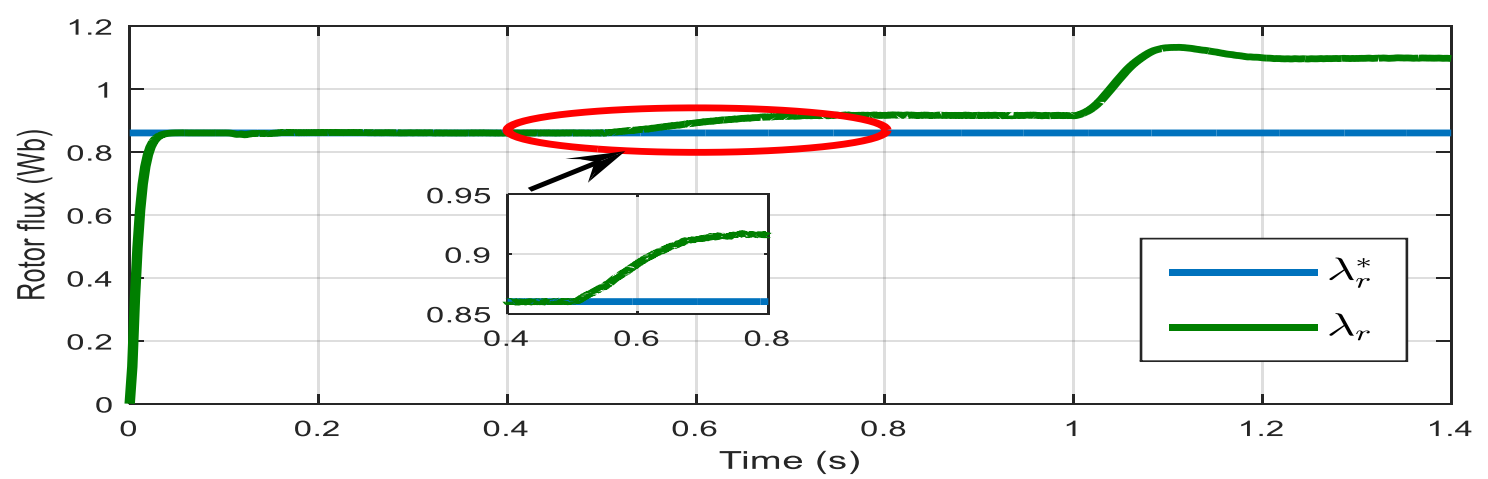

(c)

Figure 4. Dynamics of estimated rotor flux with (b) and without (c) sliding mode observer (SMO) under varying rotor resistance $(\mathbf{a})$. 


\subsection{Experimental Validation}

Experimental tests have been carried out for a $1 \mathrm{~kW}$ five-phase IM using TMS320C32 DSP based control board. Figure 5 shows the experimental results of IRFOC of the five-phase IM using only the fundamental components of the currents. The $(\alpha-\beta)$ and $(x-y)$ components of stator currents when the motor runs at 250 RPM without load $\left(T_{L}=0\right)$ are shown in Figure $5 \mathrm{a}$. The same waveforms are presented in Figure $5 b$ when a $50 \%$ of the rated load is applied to the motor at time $t=1.3 \mathrm{~s}$. Figure $5 c, d$ illustrates the waveforms of the stator currents in the $(d-q)$ and $(x-y)$ planes and the motor speed when the motor runs at 250 RPM in both cases (without load and 50\% of the rated load). The waveforms are consistent with the theoretical analysis; the stator current is a sinusoidal waveform as desired, sharing the similarity with the air-gap flux profile. From the actual speed profile, it can be realized that the IRFOC system is very stable during the steady state operation. It is observed that the speed regulation and the steady-state operation is realized very fast. However, the speed is attributed with the chattering phenomena, but it is improved by replacing the signum function with a saturation function.
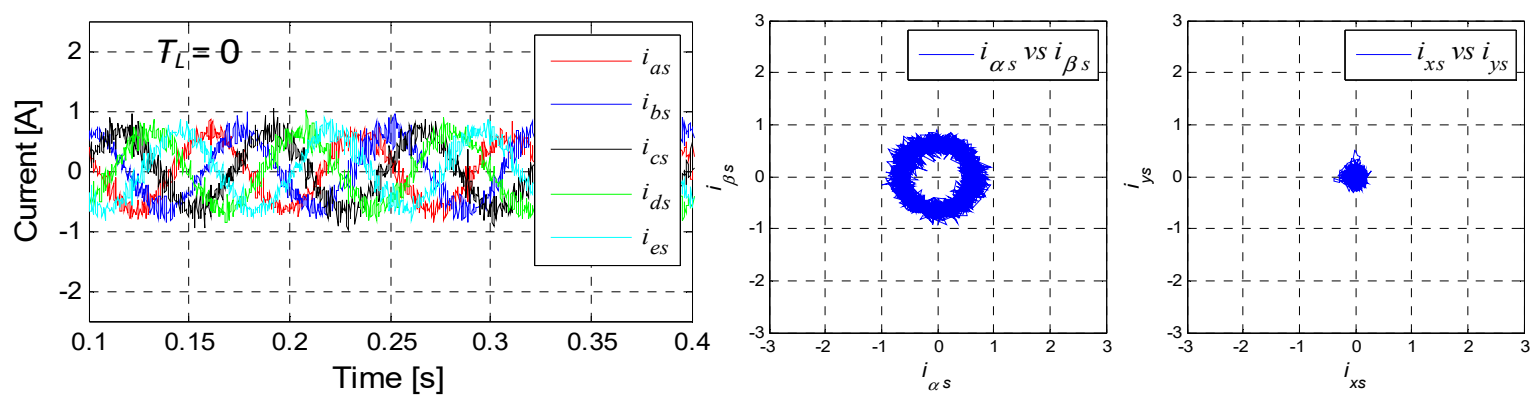

(a) Stator currents at zero load, and their representation in the $(d-q)$ and $(x-y)$ planes.
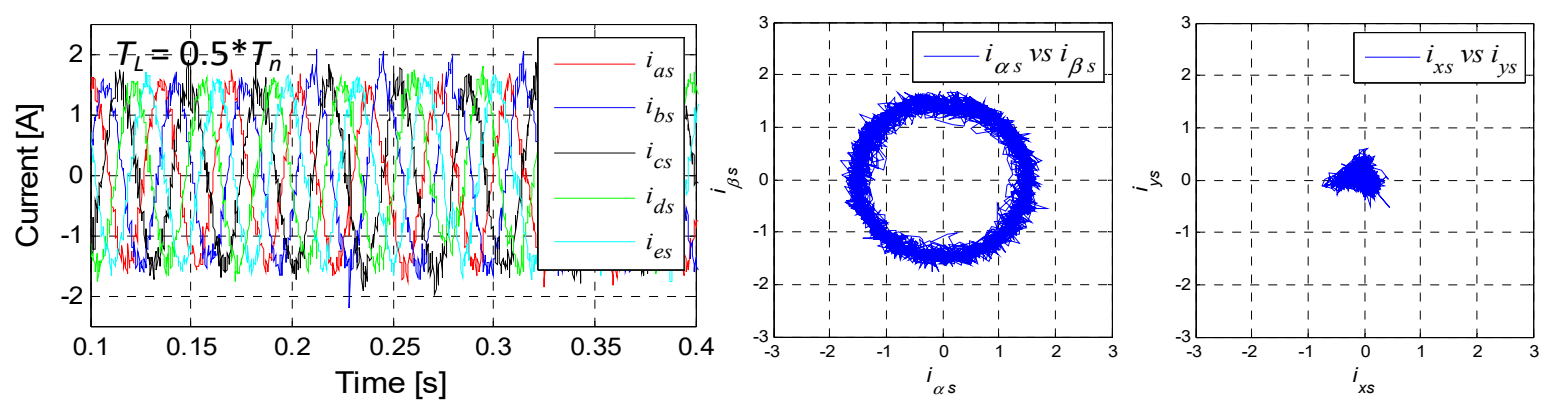

(b) Stator currents at 50\% load, and their representation in the $(d-q)$ and $(x-y)$ planes
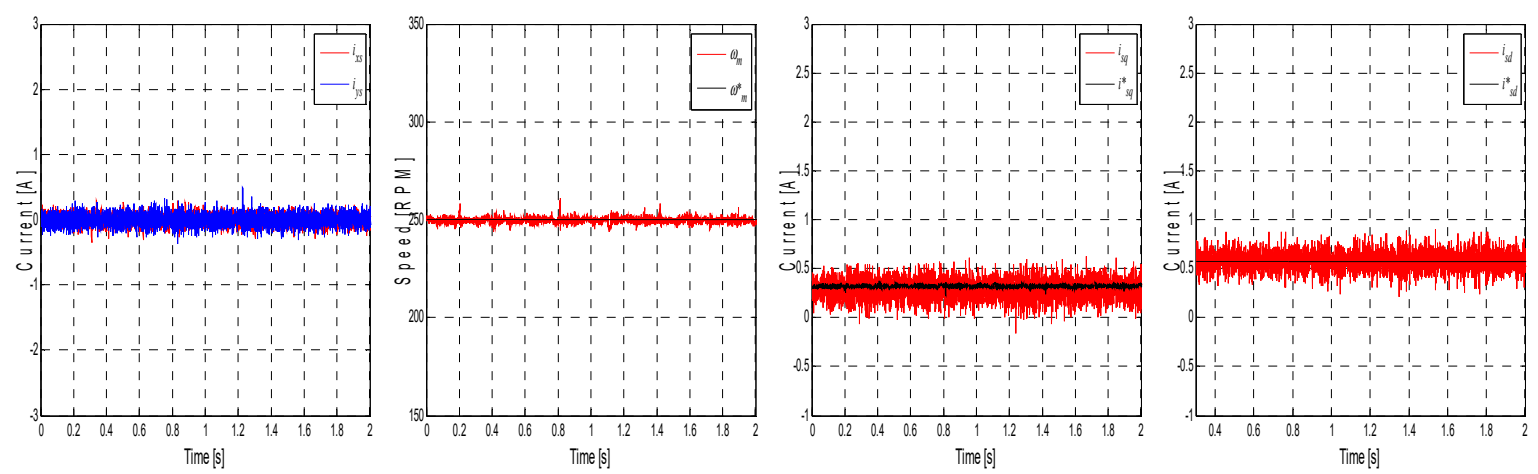

(c) $(x-y)$ current components, speed, $d$ - current component and $q$ - current component at zero load

Figure 5. Cont. 

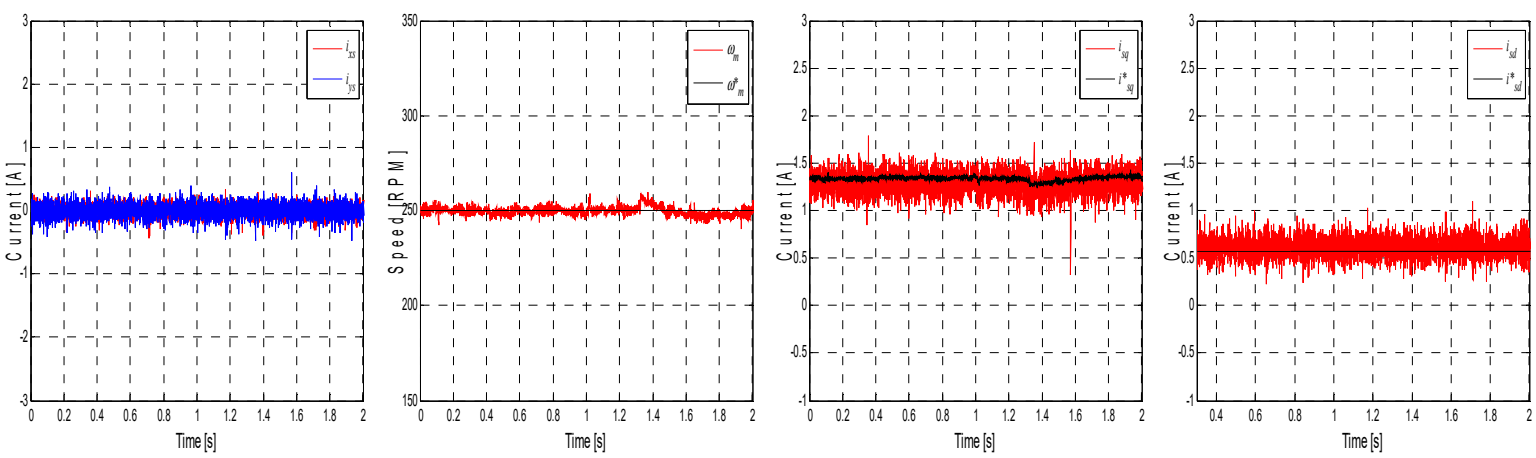

(d) $(x-y)$ current components, speed, $d$ - current component and $q$ - current component at $50 \%$ load

Figure 5. Experimental validation at operating speed of 250RPM.

The experimental tests are also carried out when operating the motor at very low speed (20 RPM), this is to investigate the validity of the SMO for a wide range of speed operation while exposing the system to uncertainties (i.e., rotor resistance variation). From Figure $6 \mathrm{a}$, it can be observed that the estimated speed tracks the actual speed with high precision. Figure $6 \mathrm{~b}$ also confirms this fact, as it shows the speed error profiles which is almost zero. Figure $6 c$ shows the torque profile, whereas Figure $6 \mathrm{~d}$ illustrates the estimated rotor flux, and from this figure, it can be realized that the proposed SMO observer has managed in achieving an accurate estimation of the rotor flux.

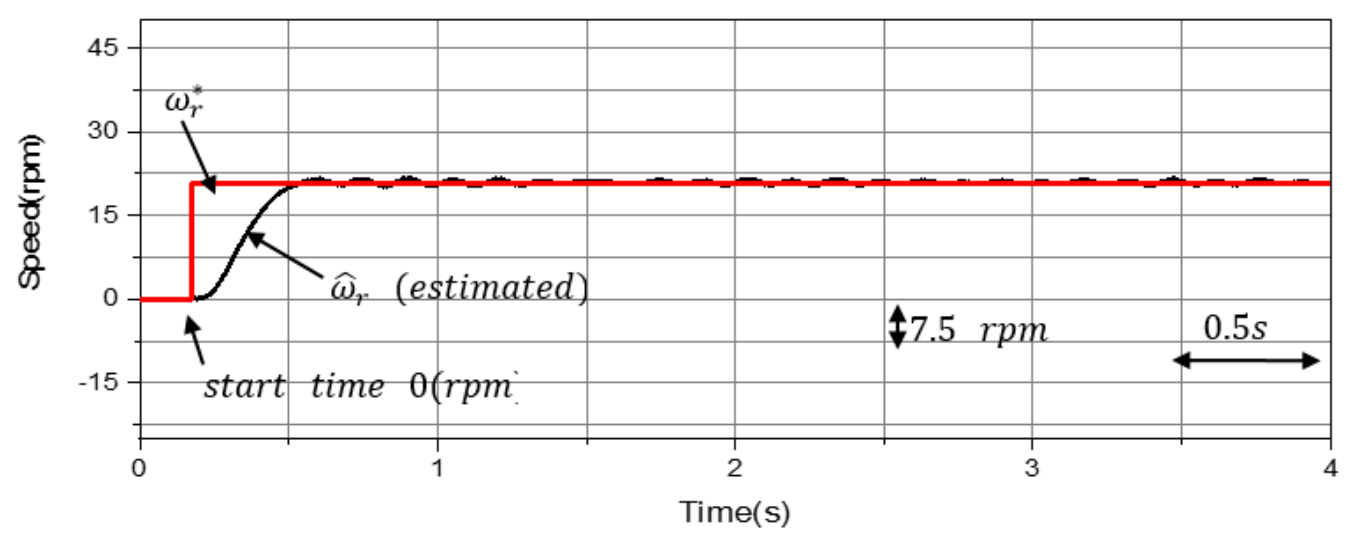

(a) Rotor speed profile (very low speed operation).

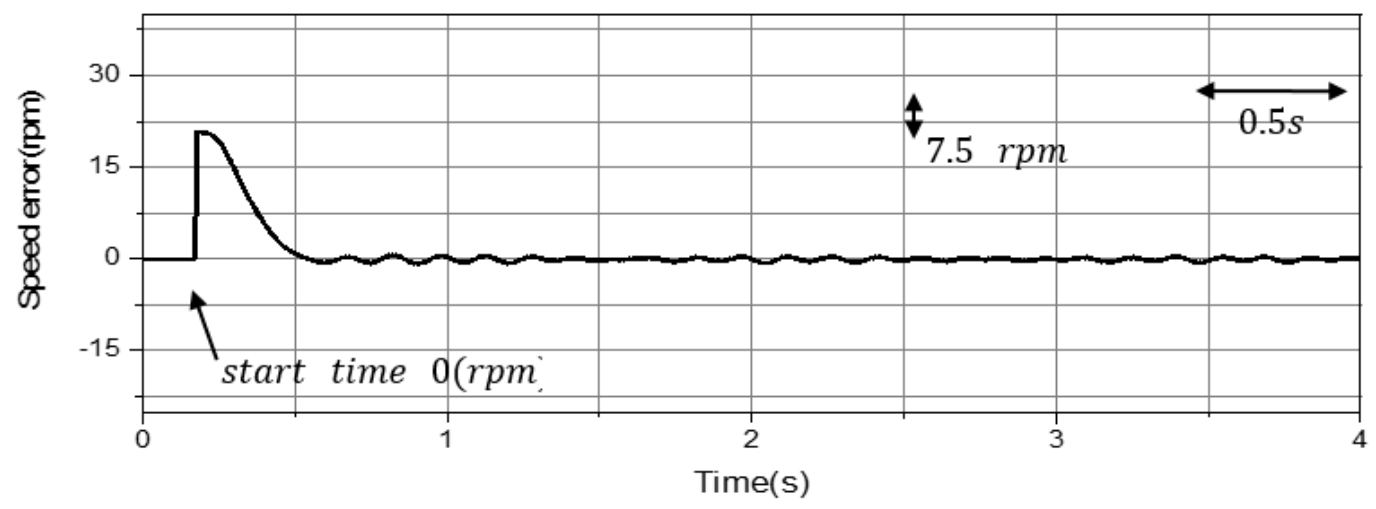

(b) Speed estimation error.

Figure 6. Cont. 


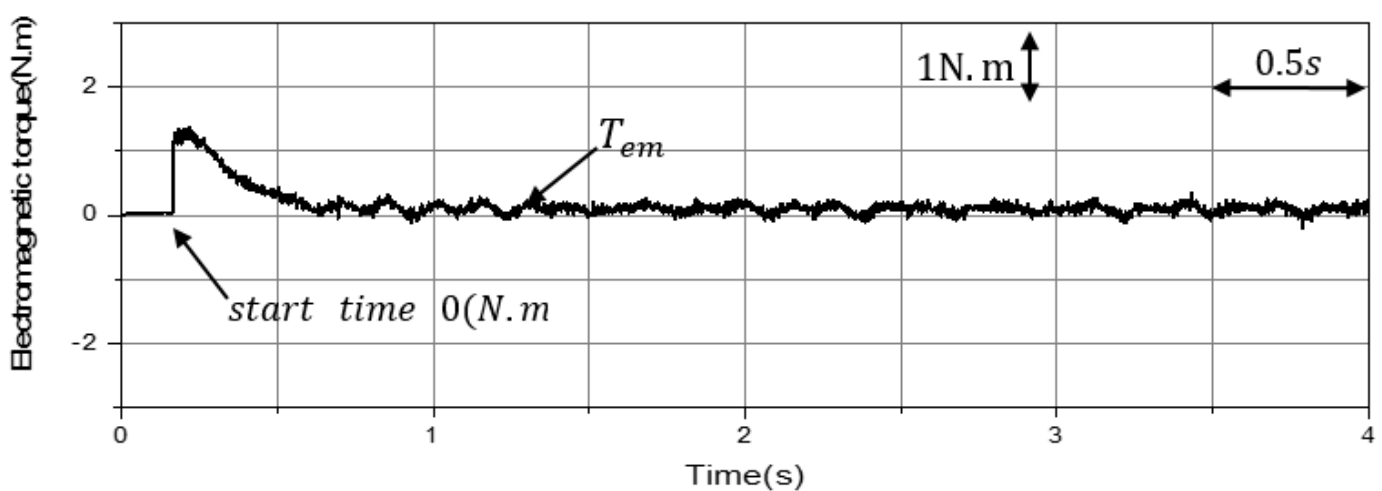

(c) Electromagnetic torque.

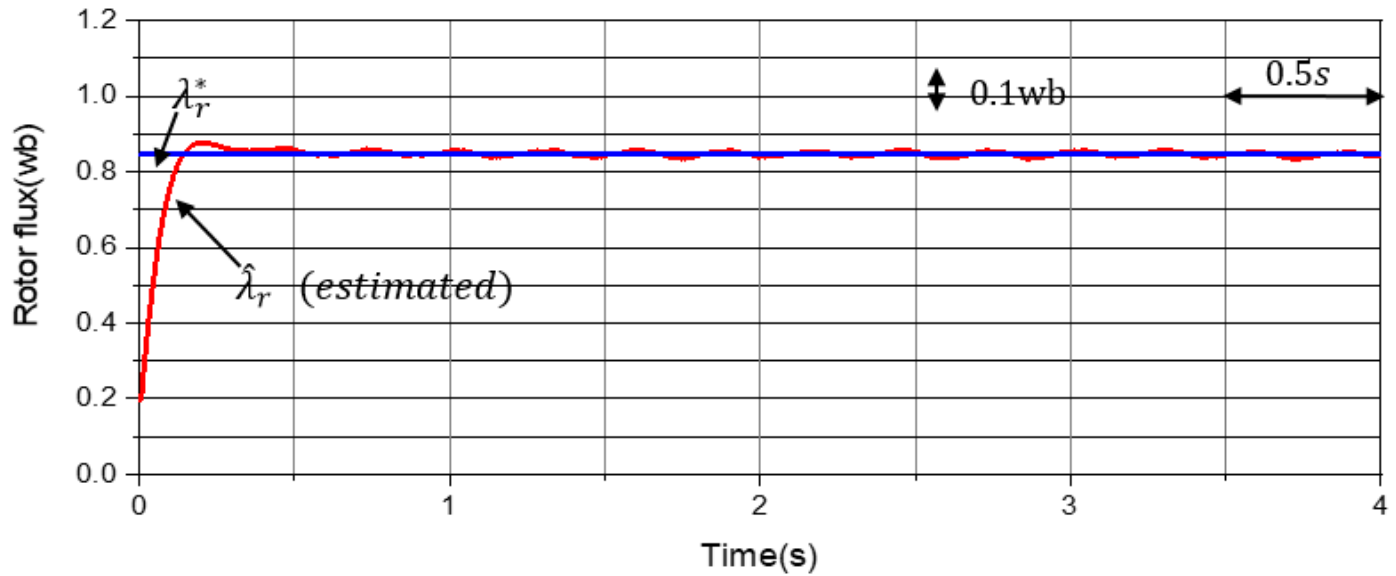

(d) Rotor flux.

Figure 6. Dynamic performance of five-phase IM drive at low speed operation.

\section{Results Discussion}

The validation of the proposed SMO observer, which is used by the IRFOC control system shown in Figure 1, has been accomplished by using three tools: the first is through using the Hardware in the loop RT simulator shown in Figure 2, the second simulation test is carried out using the Matlab/Simulink environment, and finally the third test which is performed experimentally using TMS320C32 DSP based control board. The parameters of the used five-phase IM used in the three tests are given in Table 2, and the parameters of the proposed SMO observer are given in Table 3.

For the first test shown in Figure 3, the performance of the observer is investigated at operating speed of $1000 \mathrm{RPM}$, with a sudden change in the estimated rotor resistance. This is to investigate the sensitivity of the proposed adaptive SMO observer. It is found that a sudden variation in the resistance value has a null impact on the estimated flux signal, the slight deviation demolishes and the estimated signal matches again the reference in a very short period (almost $0.2 \mathrm{~s}$ ). At last, the observer's dynamic is tested when changing the motor load at time $t=25 \mathrm{~s}$. The obtained results in Figure 3 report that the behavior of the drive is normal i.e. smooth stator currents are obtained while maintain their ratings, both rotor speed and rotor flux track effectively their reference values with minimum error and high matching precision. The obtained results in this test also confirm the high dynamic performance of the controller when changing the load torque from 0 to $70 \%$ of its rated value.

In the second test, which is carried out using the Matlab/Simulink software, the dynamic behavior of the proposed SMO observer is tested through investigating the estimated values of rotor flux, which under parameter variation, plays an important role in estimating the rotor speed. The test is performed when changing the rotor resistance value to $1.5 * R_{r n}$ at time $\mathrm{t}=0.5 \mathrm{~s}$ while observing the rotor flux with and without using the SMO observer. The obtained results in Figure 4 approved the vital role that the SMO observer plays in maintaining the estimated flux values within the reference limits. 
The third test is carried out experimentally using the TMS320C32 DSP based control board. In this test the dynamic performance of the SMO observer is tested for different operating speeds (medium and low). In Figure 5, the drive is operated at 250 RPM, with two values of load torque: 0 and $50 \%$ of rated load torque. The obtained results illustrate the feasibility of the proposed sensorless controller via obtaining sinusoidal signals of rotor flux and stator currents, while tracking precisely the reference speed and following the torque change as well.

The drive performance is also tested experimentally at very low speed operation (20 RPM), which is considered as a challenge to the SMO observer. The results shown in Figure 6 confirm and validate the effectiveness of the proposed SMO in achieving the control targets and estimating the rotor speed and rotor flux values with minimum deviations.

\section{Conclusions}

A novel two-time-scale procedure has been proposed in this paper to design an adaptive sliding mode observer (SMO) to estimate the rotor speed and rotor resistance simultaneously so that the sensorless speed control of a five-phase IM can be realized. The observing system is designed considering the stator voltages and stator currents as measured quantities. The feasibility of the proposed SMO observer with rotor resistance and speed estimations is proved using three different tools: the RT-lab real-time simulation, the Matlab/Simulnink software and experimentally using the TMS320C32 DSP based control board. High dynamic performance of the proposed SMO observer is demonstrated in terms of speed regulation and parameter sensitivity. It is further shown that the use of singular perturbation simplifies the construction of the robust observer for the five-phase IM drive while achieving the desired dynamic performance.

Author Contributions: M.A.M., H.E., and A.I.; methodology, M.A.M., H.E., and A.S.A.-S.; software, M.A.M., A.I., and T.D.D.; validation, H.E., M.A.M., and T.D.D.; formal analysis, T.D.D., A.S.A.-S., and H.E.; investigation, M.A.A. and A.I.; resources, H.E., T.D.D., and A.S.A.-S.; data curation, M.A.M. and H.E.; writing-original draft preparation, M.A.M., A.I., and T.D.D.; writing-review and editing, M.A.M. and A.I.; visualization, A.I. and T.D.D.; supervision, T.D.D. and A.S.A.-S.; project administration, A.S.A.-S.; funding acquisition. All authors have read and agreed to the published version of the manuscript.

Funding: This research was supported by department of electrical engineering and computer science, Khalifa University, Abu Dhabi 127788, UAE.

Conflicts of Interest: The authors declare no conflict of interest.

\section{References}

1. Ward, E.; Härer, H. Preliminary investigation of an inverter-fed 5-phase induction motor. Proc. Inst. Electr. Eng. 1969, 116, 980-984. [CrossRef]

2. Klingshirn, A. High Phase Order Induction Motors-Part I. Description and Theoretical Considerations. IEEE Power Eng. Rev. 1983, 1, 27.

3. Klingshirn, A. High Phase Order Induction Motors-Part II. Experimental Results. IEEE Power Eng. Rev. $1983,1,27-28$.

4. Semail, E.; Bouscayrol, A.; Hautier, P. Vectorial formalism for analysis and design of polyphase synchronous machines. Eur. Phys. J. Appl. Phys 2003, 22, 207-220. [CrossRef]

5. Mohamed, A.; Selim, F. A sensorless six-phase induction motor driving a centrifugal pump system. In Proceedings of the Nineteenth International Middle East Power Systems Conference (MEPCON), Cairo, Egypt, 19-21 December 2017; pp. 242-247.

6. Maher, A.; Pragasen, P.; Pierre, A. A Novel In Situ Efficiency Estimation Algorithm for Three-Phase Induction Motors Operating With Distorted Unbalanced Voltages. IEEE Trans. Ind. Appl. 2017, 53, 5338-5347.

7. Vo, H.; Nguyen, T.; Duong, T.; Pham, H. Sensorless speed control of a three-phase induction motor: An experiment approach. In Proceedings of the International Conference on System Science and Engineering (ICSSE), Ho Chi Minh City, Vietnam, 21-23 July 2017; pp. 694-698. 
8. Kim, J.; Lee, Y.; Lee, J. A sensorless speed estimation for indirect vector control of three-phase induction motor using Extended Kalman Filter. In Proceedings of the IEEE Region 10 Conference (TENCON) Marina Bay Sands, Singapore, 22-25 November 2016; pp. 3087-3090.

9. Son, N.; Phi, P.; Tuan, P.; Hoa, H.; Cong, N.; Phi, D. A sensorless three-phase induction motor drive using indirect field oriented control and artificial neural network. In Proceedings of the IEEE Conference on Industrial Electronics and Applications (ICIEA), Siem Reap, Cambodia, 18-20 June 2017; pp. 1454-1459.

10. Uma, S.; Jayanand, B. A reduced order smoothing filter for speed estimation of three phase induction motor. In Proceedings of the TENCON 2017-2017 IEEE Region 10 Conference, Penang, Malaysia, 5-8 November 2017; pp. 1749-1754.

11. Mario, B.; Ignacio, P.; Federico, B.; Hugo, G.; Mario, D.; Xavier, K. Open-Phase Fault-Tolerant Direct Torque Control Technique for Five-Phase Induction Motor Drives. IEEE Trans. Ind. Electron. 2016, 99, 1.

12. Jorge, R.; Federico, B.; Manuel, A.; Cristina, M.; Raul, G. Online Estimation of Rotor Variables in Predictive Current Controllers: A Case Study Using Five-Phase Induction Machines. IEEE Trans. Ind. Electron. 2016, 9 , 5348-5356.

13. Jorge, R.; Hugo, G.; Raul, G.; Federico, B. Model predictive current controller using Kalman filter for fault-tolerant five-phase wind energy conversion systems. In Proceedings of the IEEE 7th International Symposium on Power Electronics for Distributed Generation Systems (PEDG), Vancouver, BC, Canada, 14-16 July 2016; pp. 1-6.

14. Jorge, R.; Cristina, M.; Manuel, A.; Federico, B.; Raul, G. Influence of Covariance-Based ALS Methods in the Performance of Predictive Controllers with Rotor Current Estimation. IEEE Trans. Ind. Electron. 2016, 99, 1.

15. Cristina, M.; Manuel, A.; Federico, B.; Mario, D. Five-Phase Induction Motor Rotor Current Observer for Finite Control Set Model Predictive Control of Stator Current. IEEE Trans. Ind. Electron. 2016, 63, 4527-4538.

16. Wolbank, T.; Woehrnschimmel, R.; Machl, J. Zero speed sensorless control signals of induction motors with closed rotor slots. In Proceedings of the IEEE 33rd Annual IEEE Power Electronics Specialists Conference. Proceedings (Cat. No.02CH37289), Cairns, QLD, Australia, 23-27 June 2002; Volume 2, pp. 997-1002.

17. Briz, F.; Degner , M.W.; Diez, A.; Lorenz, R.D. Measuring, modeling, and decoupling of saturation-induced saliencies in carrier-signal injection-based sensorless AC drives. IEEE Trans. Ind. Appl. 2001, 5, 1356-1364.

18. Soto, G.; Mendes, E.; Razek, A. Reduced-order observers for rotor flux, rotor resistance and speed estimation for vector controlled induction motor drives using the extended Kalman filter technique. IEE Proc. Electr. Power Appl. 1999, 146, 282-288. [CrossRef]

19. Zuohua, X.; Jiuhe, W.; Pengfei, W. Passivity-based control of induction motor based on euler-lagrange (EL) model with flexible damping. In Proceedings of the International Conference on Electrical Machines and Systems, Wuhan, China, 17-20 October 2008; pp. 48-52.

20. Alma, A.; Edgar, S.; Alexander, L. Real-Time Output Trajectory Tracking using a Discrete Neural Backstepping Controller. In Proceedings of the IEEE International Symposium on Intelligent Control, San Antonio, TX, USA, 3-5 September 2008; pp. 1289-1294.

21. Bilal, A.; Umut, O.; Aydin, E. A comparative study on Kalman filtering techniques designed for state estimation of industrial AC drive systems. In Proceedings of the IEEE International Conference Mechatronics, ICM '04, Istanbul, Turkey, 3-5 June 2004; pp. 439-445.

22. Suman, M.; Chandan, C.; Yoichi, H.; Minh, T. Model Reference Adaptive Controller-Based Rotor Resistance and Speed Estimation Techniques for Vector Controlled Induction Motor Drive Utilizing Reactive Power. IEEE Trans. Ind. Electron. 2008, 55, 594-601.

23. Ramzi, T.; Adel, K.; Mouhamed, M.; Faouzi, M. Backstepping control for an induction motor using an adaptive sliding rotor-flux observer. Electr. Power Syst. Res. 2012, 93, 1-15.

24. Sravanthi, C.; James, C. A survey of energy harvesting sources for embedded systems. In Proceedings of the IEEE SoutheastCon, Huntsville, AL, USA, 3-6 April 2008; pp. 442-447.

25. Zhifeng, Z.; Renyuan, T.; Baodong, B.; Dexin, X. Novel Direct Torque Control Based on Space Vector Modulation With Adaptive Stator Flux Observer for Induction Motors. IEEE Trans. Magn. 2010, 46, 3133-3136.

26. Thomas, M.; Andreas, K. Tracking control for boundary controlled parabolic PDEs with varying parameters: Combining backstepping and differential flatness. Automatica 2009, 45, 1182-1194.

27. Toshiaki, T.; Takuya, H.; Hiroshi, K.; Mariko, M.; Kouhei, O. A Wide-Range Velocity Measurement Method for Motion Control. IEEE Trans. Ind. Electron. 2009, 56, 510-519. 
28. Teresa, K.; Mateusz, D. Stator-Current-Based MRAS Estimator for a Wide Range Speed-Sensorless Induction-Motor Drive. IEEE Trans. Ind. Electron. 2010, 57, 1296-1308.

29. Ghanes, M.; Leon, J.; Glumineau, A. Cascade and high-gain observers comparison for sensorless closed-loop induction motor control. Iet Control Theory Appl. 2008, 2, 133-150. [CrossRef]

30. Amuliu, P.; Ali, K. Sliding-Mode Flux Observer With Online Rotor Parameter Estimation for Induction Motors. IEEE Trans. Ind. Electron. 2007, 54, 716-723.

31. Adnan, D.; Mustafa, G.; Habib-ur, R.; Longya, X. A new approach to induction machine flux and speed observer with on-line rotor time constant estimation. In Proceedings of the IEMDC. IEEE International Electric Machines and Drives Conference (Cat. No.01EX485), Cambridge, MA, USA, 17-20 June 2001; pp. 102-107.

32. Adel, K.A.; Mohamed, M. Sensorless-adaptive DTC of double star induction motor. Energy Convers. Manag. 2010, 51, 2878-2892.

33. Abdelkrim, B.; Ahmed, R.; Eric, A. Sliding mode input-output linearization and field orientation for real-time control of induction motors. IEEE Trans. Power Electron. 1999, 14, 3-13.

34. Ramzi, T.; Adel, K.; Mohamed, M.; Faouzi, M. Backstepping control for an induction motor with an adaptive Backstepping rotor flux observer. In Proceedings of the Control \& Automation (MED), 18th Mediterranean Conference, Marrakech, Morroco, 24-26 June 2010; pp. 5-10.

35. Soltani, J.; Payam, F.; Abbasian, M. A Speed Sensorless Sliding-Mode Controller for Doubly-Fed Induction Machine Drives with Adaptive Backstepping Observer. In Proceedings of the IEEE International Conference on Industrial Technology, Mumbai, India, 15-17 December 2006; pp. 2725-2730.

36. Prut, N.; Suwat, K. Observer-based backstepping force control of an electrohydraulic actuator. Control Eng. Pract. 2009, 17, 895-902.

37. Jalalifar, M.; Farrokh Payam, A.; Mirzaeian, B.; Saghaeian nezhad, S.M. Dynamic Modeling and Simulation of an Induction Motor with Adaptive Backstepping Design of an Input-Output Feedback Linearization Controller in Series Hybrid Electric Vehicle. In Proceedings of the International Conference on Power Electronic, Drives and Energy Systems, New Delhi, India, 12-15 December 2006; pp. 1-6.

38. Khadar, S.; Kouzou, A.; Hafaifa, A.; Atif, I. Investigation on SVM-Backstepping sensorless control of five-phase open-end winding induction motor based on model reference adaptive system and parameter estimation. Eng. Sci. Technol. Int. J. 2019, 22, 1013-1026.

39. Kan, A.; Atsuo, K. Sensorless very low-speed and zero-speed estimations with online rotor resistance estimation of induction motor without signal injection. IEEE Trans. Ind. Appl. 2000, 36, 764-771.

40. Murat, B.; Seta, B.; Metin, G. Switching EKF technique for rotor and stator resistance estimation in speed sensorless control of IMs. Energy Convers. Manag. 2007, 48, 3120-3134.

41. Francesco, A.; Filippo, D.; Antonino, S. Sensorless Control of Induction-Motor Drive Based on Robust Kalman Filter and Adaptive Speed Estimation. IEEE Trans. Ind. Electron. 2014, 3, 1444-1453.

42. Jakub, T.; Zdenek, P.; Vojtech, B.; Lubos, S. Rotor and stator resistance estimation of induction motor based on augmented EKF. In Proceedings of the International Conference on Applied Electronics (AE), Pilsen, Czech Republic, 8-9 September 2015; pp. 253-258.

43. Jiménez, E.; Jaramillo, O.; Sánchez-Torres, J.; Boteroy, H. A second order sliding mode state and parameter estimator for induction motors. In Proceedings of the 12th International Conference on Electrical Engineering, Computing Science and Automatic Control (CCE), Mexico City, Mexico, 28-30 October 2015; pp. 1-6.

44. Deepak, P.; Ashok, S. Sensorless speed estimation of linear induction motor under variable discrete loading using cascaded MRAS observer. In Proceedings of the International Conference on Emerging Trends in Electrical Electronics \& Sustainable Energy Systems (ICETEESES), Ratan Pur, India, 11-12 March 2016; pp. 274-279.

45. Mihai, C. Design of a MRAS-type sliding mode observer for estimation of the rotor time constant of the induction motor. In Proceedings of the IECON-42nd Annual Conference of the IEEE Industrial Electronics Society, Florence, Italy, 23-26 October 2016; pp. 2573-2748.

46. Haitam, C.; Ahmed, E.; Tamou, N. MRAS and Luenberger observers using a SIFLC controller in adaptive mechanism based sensorless fuzzy logic control of induction motor. In Proceedings of the International Conference on Electrical and Information Technologies (ICEIT), Tangiers, Morocco, 4-7 May 2016; pp. 153-158. 
47. Djemai, M.; Hernande, J.; Barbot, J. Nonlinear control with flux observer for a singularly perturbed induction motor. In Proceedings of the 32nd IEEE Conference on Decision and Control, San Antonio, TX, USA, 15-17 December 1993; Volume 4, pp. 3391-3396.

48. De-Leon, J.; Alvarez, J.; Castro, R. Sliding mode control and state estimation for nonlinear singularly perturbed systems. Application to an induction electric machine. In Proceedings of the International Conference on Control Applications, Albany, NY, USA, 28-29 September 1995; pp. 998-1003.

49. Hamdy, E.; Ramzi, T.; Atif, I.; Faouzi, M. Real time implementation of indirect rotor flux oriented control of a five-phase induction motor with novel rotor resistance adaption using sliding mode observer. J. Frankl. Inst. 2018, 355, 2112-2141.

50. Abdelkrim, B.; Ahmed, R.; Eric, A.; Mohamed, T. Real-time sliding-mode observer and control of an induction motor. IEEE Trans. Ind. Electron. 1999, 46, 128-138.

51. Hamdy, E.; Ramzi, T.; Atif, I.; Nichola, B.; Faouzi, M. Non-linear backstepping control of five-phase IM drive at low speed conditions-experimental implementation. Isa Trans. 2016, 65, 244-253.

52. Mezouar, A.; Fellah, M.; Hadjeri, S. Adaptive sliding-mode-observer for sensorless induction motor drive using two-time-scale approach. Simul. Model. Pract. Theory 2008, 16, 1323-1336. [CrossRef]

53. Proca, A.; Keyhani, A.; Miller, J. Sensorless sliding mode control of induction motors using operating condition dependent models. IEEE Trans. Energy Convers. 2003, 18, 205-212. [CrossRef]

54. Min, J.; Bong, J.; Jun, J.; Yong, P.; Young, K. Speed sensorless control of induction motor using sliding mode observer with variable boundary layer. In Proceedings of the SICE Annual Conference, Tokyo, Japan, 20-22 August 2008; pp. 748-752.

55. Atassi, A.; Khalil, H. A separation principle for the control of a class of nonlinear systems. IEEE Trans. Autom. Control 2001, 46, 742-746. [CrossRef]

56. Chengkang, X. An output feedback control design via nonlinear separation principle. In Proceedings of the 7th World Congress on Intelligent Control and Automation (WCICA), Chongqing, China, 25-27 June 2008; pp. 2886-2889.

57. Sassano, M.; Astolfi, A. A Local Separation Principle via Dynamic Approximate Feedback and Observer Linearization for a Class of Nonlinear Systems. IEEE Trans. Autom. Control 2019, 64, 111-126. [CrossRef]

(C) 2020 by the authors. Licensee MDPI, Basel, Switzerland. This article is an open access article distributed under the terms and conditions of the Creative Commons Attribution (CC BY) license (http://creativecommons.org/licenses/by/4.0/). 